ÉGYPTE monde arabe

\section{Égypte/Monde arabe}

4-5 | 2001

L'Égypte dans le siècle, 1901-2000

\title{
Officiers et Frères musulmans : 1945-1948
}

\section{Tewfik Aclimandos}

\section{(2) OpenEdition}

\section{Journals}

Édition électronique

URL : https://journals.openedition.org/ema/887

DOI : 10.4000/ema.887

ISSN : 2090-7273

\section{Éditeur}

CEDEJ - Centre d'études et de documentation économiques juridiques et sociales

\section{Édition imprimée}

Date de publication : 30 juin 2001

Pagination : 255-306

ISBN : 2-87027-963-9

ISSN : $1110-5097$

\section{Référence électronique}

Tewfik Aclimandos, «Officiers et Frères musulmans : 1945-1948 », Égypte/Monde arabe [En ligne], 4-5 | 2001, mis en ligne le 08 juillet 2008, consulté le 07 juillet 2022. URL : http://journals.openedition.org/ ema/887 ; DOI : https://doi.org/10.4000/ema.887

Ce document a été généré automatiquement le 7 juillet 2022

Tous droits réservés 


\title{
Officiers et Frères musulmans : 1945-1948
}

\author{
Tewfik Aclimandos
}

1 Si les années trente voient l'apparition de courants culturels ${ }^{1}$ et de forces politiques ${ }^{2}$ hostiles au pacte ${ }^{3}$ prévalant - c'est-à-dire l'équilibre précaire, réel mais que les partis veulent toujours renégocier, entre une monarchie autoritaire à légitimité semireligieuse et un parti majoritaire semi-laïque -, les années quarante sont celles de l'irrésistible montée en puissance de l'une d'elles, les Frères musulmans ${ }^{4}$. L'étude des origines du mouvement des officiers libres et de la trajectoire des officiers gravitant autour d'eux permet également de retracer les tentatives d'infiltration de l'armée par les Frères.

2 Ces tentatives, menées par Hasan al-Bannâ personnellement et par le commandant Mahmûd Labîb ${ }^{5}$, ancien militaire et secrétaire général des Frères musulmans, permirent de constituer plusieurs cellules, affiliées aux Frères, mais jouissant d'une grande autonomie. Les Frères furent, on le verra, confrontés à un problème: une majorité d'activistes étaient nationalistes plutôt qu'islamistes, mais étaient désireux de collaborer avec eux et éprouvaient de la sympathie pour le mouvement, tout en n'adhérant pas à ses thèses, et surtout à sa pratique. Se mit en place, cahin-caha, une «drôle d'allégeance" (Khâlid Muhyî al-Dîn, 1992) ${ }^{6}$, et une collaboration, une cohabitation, dont nous tenterons d'écrire l'histoire, à partir des témoignages disponibles. Certains officiers restèrent Frères jusqu'au bout; d'autres mirent un terme à leur collaboration à des dates et pour des raisons diverses. Malgré la multitude des trajectoires individuelles, dont nous nous efforcerons de restituer la richesse, il semble pertinent d'écrire que la collaboration prit fin en 1949, avec la "défection » et la «rupture " entre Nâsir [Nasser], ses camarades et les Frères, et la création du mouvement des Officiers libres, à vocation « supra-partisane ».

3 Nous excluons l'explication - de l'engagement politique, de l'action collective, du choix en faveur des Frères musulmans - par l'origine sociale. Affirmer que les militaires ayant adhéré aux Frères sont dans leur majorité originaires des classes moyennes provinciales ou d'origine provinciale, ne nous avance guère ${ }^{7}$, car il est difficile 
d'expliquer l'adhésion aux Frères par cette origine, partagée par un grand nombre de militaires.

4 La présence étrangère est un facteur plus pertinent. Mais, ressentie par de larges secteurs de la population, elle n'explique pas spécifiquement la mobilisation politique de certains groupes et, a fortiori, l'adhésion aux Frères. La dichotomie provincial/ cairote est également digne d'intérêt, mais doit être maniée avec précaution, ne seraitce que parce que la plupart des citadins ont des racines rurales. Implique-t-elle l'opposition entre deux "cultures », une plus égypto-islamique, l'autre plus sensible aux apports étrangers ? Dans ce cas, elle n'est pas opératoire, car falsifiée par les faits. Ni les idéologies importées ni le modernisme radical musulman n'ont de véritable prise hors des cercles intellectuels ${ }^{8}$. Sous-tend-elle des difficultés de socialisation et de valorisation de soi ou une grande disponibilité qui serait l'apanage des provinciaux et des nouveaux citadins, semblables à celles diagnostiquées pour la jeunesse par

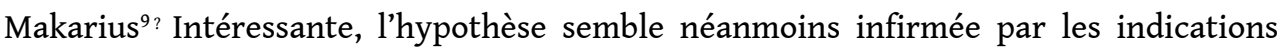
dont nous disposons: l'armée intègre bien; les officiers n'éprouvent guère de difficultés majeures, peuvent se marier vite et profitent pleinement des « opportunités » qu'offre la capitale en matière de culture et de loisirs. D'autre part, il y a des « citadins cairotes" engagés en politique aux côtés des Frères ('Abd al-Ra'ûf). Ce qui semble très pertinent dans le cas des lycéens et des étudiants l'est nettement moins dans celui des jeunes officiers. Reste l'explication par "l'habitude»: en tant que lycéens, certains, plutôt les "exilés", provinciaux ou nouveaux citadins, prirent l'habitude de s'occuper de politique, du rapport avec les valeurs centrales et ne la perdirent pas. Les éléments dont nous disposons sont contradictoires: nous connaissons certes de nombreux cas d'activistes lycéens devenant des activistes militaires - Nâsir, 'Abd al-Ra'ûf, Tawfîq A. Ismâ̂îl, pour ne parler que des sympathisants des «Frères » - mais l'on peut aussi citer des activistes lycéens devenant des militaires sans engagement politique, comme cAbd al-Muncim Riyâd. Enfin, de nombreux militaires activistes n'ont pas mentionné leur engagement estudiantin, ce qui peut laisser supposer qu'ils n'en ont pas eu. L'appartenance à une génération précise d'Égyptiens, née entre 1917 et 1922, et au corps des officiers, tel qu'il se constitua après les réformes de 1936, demeure, elle aussi, une variable pertinente: un groupe, ayant une expérience commune, une mémoire partagée et plusieurs conceptions ou orientations suffisantes pour rendre possible un agir collectif vers un objectif commun, se forma. Ceci, bien sûr, n'occulte pas la multitude des trajectoires, efforts, savoirs, « mentalités » et Weltanschauungs, individuelles ou « de classe ». Ceci n'explique pas non plus pourquoi certains agissent et d'autres non, pourquoi certains sont concernés par le politique, d'autres moins ou pas du tout, et pourquoi certains sont marxistes et d'autres Frères. Les explications par l'origine sociale ou encore par une éventuelle chute du pouvoir d'achat ne nous aident guère plus. Nous tenterons, quant à nous, non une explication par les "mentalités » ou la "culture », mais une description des modalités selon lesquelles les acteurs, ayant décidé d'agir, perçoivent le réel et effectuent leurs choix.

5 Hasan al-Bannâ, dès la fin des années trente, perçoit l'utilité d'une «infiltration » de l'armée par son mouvement, dans le cadre d'une éventuelle prise du pouvoir ${ }^{10}$. Conscient de son charisme et de l'importance de l'enjeu, il s'en occupe personnellement. Avec l'accord du Palais, il prend la parole, lors des fêtes religieuses, telles que la naissance du Prophète ou la victoire de 'Uhud, devant des unités de 
l'armée. Il charge Mahmûd Labîb de fonder et constituer des cellules «Frères » dans l'armée et la police. Il remportera quelques succès avec les sous-officiers, les appelés et les ouvriers d'entretien. Dès 1941, un groupe de «soldats" affiliés aux Frères est signalé par un rapport de police ${ }^{11}$. Ce groupe envoie une pétition au Roi, réclamant entre autres l'abrogation du traité de 1936, la libération de 'Azîz al-Masrî, l'arrestation de toute égyptienne vue avec un soldat britannique, et le droit pour les soldats de « combattre ce qui est contraire à la loi » (version de la «commanderie du bien et du pourchas du mal»).

Les Frères recrutent ${ }^{\mathrm{c}} \mathrm{Abd}$ al-Muncim ${ }^{\mathrm{c}} \mathrm{Abd}$ al-Ra'ûf

La situation change en juin 1942, avec l'adhésion de 'Abd al-Muncim 'Abd al-Ra'ûf. Celuici, selon ses propres dires, a appris en mars 1942 l'existence de ce mouvement, en découvrant, dans le bureau d'un fonctionnaire, une de ses publications ${ }^{12}$. Cette découverte, pour un mouvement qui a déjà des dizaines, voire des centaines de milliers d'adhérents (250 000 en 1940, selon al-Bannâa ${ }^{13}$ ) peut sembler étonnante, mais le récit de 'Abd al-Ra'ûf montre qu'il ignorait effectivement l'existence de ce mouvement. Soit le « cloisonnement » et l'autonomisation du corps des officiers, processus qui commence à l'Académie militaire, sont très poussés; soit le nationalisme de 'Abd al-Ra'ûf (et de Hammûda, qui, lui aussi, «découvrira " ${ }^{14}$ ) va de pair avec une méconnaissance complète de la vie sociale et politique égyptienne, comme une absence d'intérêt pour elle, chose assez curieuse pour l'ancien leader politique lycéen qu'est 'Abd al-Ra'ûf; soit, enfin, le mouvement, « ignoré » (selon ses adhérents) par la presse nationale, est beaucoup plus « souterrain » qu'on ne le supposait.

7 Quoi qu'il en soit, il se rend au siège des Frères, un mardi, et ce qu'il voit le frappe ${ }^{15}$ : «À l'entrée du bâtiment, je vis un jeune homme qui avait, dans un coin, aligné des dizaines d'ouvrages islamiques. Je vis un groupe de jeunes occupés à sortir des chaises et à les nettoyer, d'autres faire leurs ablutions ; je n'entendais ni prières ni dhikr ni demande de pardon. Le mu'azzin arriva pour la prière du maghrib, 300 fidèles firent ensemble la prière, puis s'assirent pour écouter, dans le plus grand calme, la prédication du mardi. Le silence n'était brisé que par les puissants slogans: Dieu est notre objectif, le Prophète notre leader, le Coran notre constitution, le Jihâd notre voie, la mort sur la voie de Dieu notre plus cher espoir. » Après son laïus, le "prédicateur " répond patiemment aux questions de l'assistance, instaurant ainsi un dialogue avec elle. ${ }^{\mathrm{A}} \mathrm{Abd}$ al-Ra'ûf ne nous donne guère de précisions sur les thèmes abordés. Mais, à titre d'exemple, Ahmad ${ }^{\mathrm{C}}$ Âdil Kamâl, qui adhère lui aussi en $1942^{16}$, indique que les premiers laïus auxquels il assista, ceux du shaykh al-Tamîmî, portaient sur "l'obéissance » (qui ne l'impressionna guère), sur « l'espoir et la confiance en la victoire de Dieu, malgré la décadence des musulmans » : deux thèmes relatifs à la " praxis ". 'Abd al-Ra'ûf est très impressionné par "l'esprit collectif, les idées islamiques, les discussions franches et utiles » et aussi, visiblement, par l'ordre et la discipline qui règnent. Il insiste dans son récit sur le « calme » discret des Frères, sur l'absence de tapage, de bruit, synonymes en Égypte de désordre. Il précise qu'il ne rencontra pas tout de suite le Guide suprême, qui était en déplacement en province ${ }^{17}$.

Celui-ci est de retour fin mai. cAbd al-Ra'ûf va le voir et lui dit que si «l'esprit "Frère" tel qu'il l'avait observé régnait au sein de l'armée égyptienne, ceci ne manquerait d'avoir des conséquences bénéfiques, et que la première chose à faire était de fonder un groupe d'officiers adoptant les principes des Frères musulmans, à savoir la justice, la force, la liberté. Ce groupe devrait être la racine donnant naissance à des cellules se 
répandant au sein de l'armée $»^{18}$. Al-Bannâ ne peut, bien sûr, qu'approuver, et ajoute que son proche collaborateur, le commandant (retraité) Mahmûd Labîb, supervisera les activités des « Frères » au sein de l'armée. L'engagement de cAbd al-Ra'ûf, qui sera total, sans compromission, qui force le respect, est difficile à expliquer par d'autres considérations que le libre choix - ou la grâce. Quand il rencontre les Frères musulmans, il vient de réintégrer les forces armées, même si l'armée de l'air lui est interdite à cause de ce qu'il prend pour des "faits de nationalisme ", et qui l'étaient en quelque sorte dans le contexte de l'époque ${ }^{19}$. Il est peut-être amer, ou déstabilisé par cet « exil », mais nous ne voyons nulle trace de cette amertume ou de cette déstabilisation. Il n'est pas au chômage et son nouveau métier (armée de terre) l'intéresse et le stimule $^{20}$. Une bonne partie, voire une nette majorité, du corps des officiers le considère comme un héros. Il est marié. Il est d'origine sociale aisée : fils d'officier, neveu de Fadlî 'Abd al-Halîm, notable wafdiste qui a partagé avec le grand Zaghlûl l'exil aux Seychelles. Il maîtrise la technique moderne. Il n'est ni déclassé ni frustré. Il ne souffre pas de problèmes d'adaptation au monde. Il n'est pas un « rural » découvrant la ville et la rejetant. Il a 28 ans et une maturité que les autres officiers activistes n'ont pas encore. Il est nationaliste? Il n'est pas le seul. Traditionaliste? Il n'est pas le seul. Pieux? La «mentalité» politique qui est la sienne à l'époque le prédispose favorablement à l'égard des Frères ? Il n'est pas le seul. Est-il, comme le laisse entendre sa remarque, exaspéré par l'état de l'armée ? Encore une fois, il n'est pas le seul. L'on pourra expliquer les adhésions d'autres officiers aux «Frères " par une sorte de souci d'efficacitée ${ }^{21}$, c'est-à-dire par le désir de faire partie d'un mouvement de masse, de savoir que l'activité que l'on déploie s'inscrit dans un effort collectif important, garant de l'utilité individuelle. Ou par un malentendu. Avec 'Abd al-Ra'ûf, ces explications ne semblent pas pertinentes. Néanmoins nous n'affirmons pas que son expérience passée ne joua aucun rôle dans cet engagement, même si elle ne permet pas de prédire son caractère héroïque et exemplaire.

Dans un texte qu'il a écrit en 1954, et qu'il cite dans ses Mémoires, 'Abd al-Ra'ûf affirme : "Quand j'étais en prison et que j'attendais (les résultats de) l'instruction dans l'affaire de 'Azîz al-Masrî, j'arrivai aux conclusions suivantes : a) l'on ne peut expulser les Britanniques que par une coopération de l'armée et du peuple ; b) la foi et l'argent sont le nerf des mouvements patriotiques; c) tout lutteur doit s'appuyer sur un organisme populaire, organisé et puissant. $\rrbracket^{22} \mathrm{Ce}$ texte fait allusion aux énormes difficultés financières et "sociales" que connaît son épouse après son arrestation. La solde de 'Abd al-Ra'ûf n'est plus versée par le ministère, elle se retrouve dans l'incapacité de payer son loyer et doit aller vivre chez son père, qui subvient à ses besoins. Quand ${ }^{\mathrm{A}} \mathrm{Abd}$ al-Ra'ûf est en prison, les amis et cousins de la famille, par crainte des tracasseries policières, cessent de rendre visite à sa famille ${ }^{23}$. La famille de 'Abd al-Ra'ûf, semblable à de nombreuses familles des couches supérieures des classes moyennes, est certes prestigieuse et aisée, mais elle n'épargne pas beaucoup, et la gêne n'est jamais très loin. Le réseau de solidarité entre officiers, qui se met en place un an plus tard, lors de l'arrestation de Sâdât [Sadate] ${ }^{24}$ - les officiers de son mouvement et/ou de sa promotion (février 38) se cotisent pour assurer à la famille du détenu une somme mensuelle équivalant à sa solde - n'existe pas encore. Cette inefficacité de la solidarité familiale et cette fragilité financière caractéristique des classes moyennes de l'époque ${ }^{25}$ marquent profondément 'Abd al-Ra'ûf. Outre ses pudiques allusions, ici et là, une remarque de Sâdât ${ }^{26}$, fait allusion, devant Mûsâ Sabrî, à l'épreuve que connut l'aviateur, et nous 
savons que l'argument majeur de 'Abd al-Ra'ûf, quelques années plus tard, pour que les Officiers libres rejoignent les Frères sera : « notre activité est risquée, et il faut, s'il nous arrive quelque chose, que quelqu'un s'occupe de nos familles " (voir infra). Un individu marié ne peut risquer la vie et l'avenir de sa conjointe et de ses enfants. Y penser n'est pas incompatible avec l'héroïsme - 'Abd al-Ra'ûf le prouvera amplement. En ce moment, il ne veut pas renoncer à l'activisme politique pour la défense des valeurs centrales, mais il ne veut plus d'action individuelle ou d'action de petit groupe, sans réseau de solidarité et de protection. Pour utiliser une métaphore économique, il est "demandeur ", et l'offre, pour un officier musulman conservateur, probablement antiwafdiste (le 4 février 1942 a eu lieu entre-temps), n'est pas très diversifiée. Il n'y a, comme formation populaire puissante et hostile au pacte politique, que les Frères musulmans.

Malgré un risque de provocation inutile, nous ne pouvons nous empêcher de souligner le fait suivant: 'Abd al-Ra'ûf, qui est le premier à adhérer aux Frères, est aussi le premier dont le premier contact avec le mouvement ne passe pas par Hasan al-Bannâ. Ce qui le séduit, nous l'avons vu, c'est l'esprit collectif, la discipline, les discussions islamiques. Il est permis de se demander si al-Bannâ, en voulant, avec Sâdât et les aviateurs, (ab)user de son charme et de son charisme personnels, ne s'est pas trompé de cible: certes, ils ont été séduits, mais cette séduction, combinée aux prétentions politiques affichées d'al-Bannâ, et au flou de son programme, semble avoir suscité leur méfiance. Les choses, nous en convenons, sont plus complexes. Beaucoup d'officiers adhèreront, peu resteront, et il faut expliquer cela autrement que par le premier contact. Mais il semble probable que 'Abd al-Ra'ûf a été séduit par son intuition des dimensions socialisatrice et sacralisatrice du mouvement («communauté de croyants ») et que les aviateurs et Sâdât ${ }^{27}$ ont été heurtés par la dimension " obédience inconditionnelle à un (pouvoir, entrepreneur) religieux ayant des objectifs politiques ", et que la différence de perception s'explique en partie par la tactique d'al-Bannâ et par le fait que les aviateurs voulaient «agir» immédiatement, contrairement à cAbd alRa'ûf.

Quoi qu'il en soit, 'Abd al-Ra'ûf entreprend de « convertir » des officiers. Au début, il n'opère qu'au sein du $3^{e}$ bataillon d'infanterie auquel il est affecté. Son premier candidat est Nâsir, qu'il présente à al-Bannâ en octobre 1942. Le second sera le lieutenant Husayn Hammûda qui s'engagera totalement au sein du mouvement d'alBannâ. Lui aussi est un jeune nationaliste, traumatisé par le 4 février 1942, qui « emplit son coeur de haine pour les Anglais »; lui aussi a fréquenté régulièrement 'Azîz alMasrî̀. Hammûda a raconté" son "recrutement » par 'Abd al-Ra'ûf. Celui-ci, à la fin de 1943, l'accoste au mess, engage une conversation, lui dit qu'il a noté sa "conscience professionnelle ", son sérieux à l'entraînement et son attachement aux principes de bonne morale (tamassukî bi-l-akhlâq al-karîma). 'Abd al-Ra'ûf lui fixe alors un rendezvous à son domicile. Là-bas, il lui dit « en substance que l'état de l'Égypte ne peut faire plaisir à personne, l'occupant britannique écrase le pays et rend impossible tout progrès ; la corruption sévit dans tous les appareils d'État, le pays est gouverné par un roi négligent, englué dans la dépravation et le stupre, entouré d'une cour dont le seul souci est d'assouvir ses caprices et se remplir les poches avec de l'argent harâm, au détriment du peuple miséreux (...) ; le salut ne peut venir que d'une révolution armée, préparée par les jeunes sincères, tant dans l'armée qu'au sein du peuple. J'approuvais... ». cAbd al-Ra'ûf le met ensuite en contact avec M. Labîb, qui lui explique 
« qui sont » les Frères musulmans : «Les "Frères" sont un groupe de musulmans s'étant promis d'œuvrer conformément au livre de Dieu et à la sunna de son prophète, à former une nouvelle génération de jeunes croyant aux préceptes de l'islam et voulant islamiser tous les aspects de la vie de l'umma islamique. » Les rencontres avec 'Abd al-Ra'ûf et Labîb se multiplient, et, quand Hammûda se sent prêt, quelques mois plus tard, il demande à rencontrer al-Bannâ. Il est impressionné par la culture de ce dernier, sa « compréhension éclairée » du livre et de la sunna et sa capacité à appuyer toute thèse par une référence au Coran ou à un hadith.

Hammûda donne ensuite, de façon indirecte, une indication importante. En laissant entendre qu'il est la première recrue de 'Abd al-Ra'ûf à adhérer aux Frères, avant Nâsir et Kamâl Husayn - ce fait est confirmé par l'historien islamiste Usâma Himayd ${ }^{30}$-, il révèle les hésitations de Nâsir, contacté avant lui. Toutefois, ce n'est pas là le seul intérêt de son récit. Celui-ci nous indique comment 'Abd al-Ra'ûf dut s'y prendre avec Nâsir et ce qui retint son attention chez ce dernier. Il nous donne des précisions sur les thèmes abordés lors des "travaux d'approche». Soulignons également que Husayn Hammûda, qui est Frère, indique les intentions de ce mouvement en matière de prise du pouvoir ${ }^{31}$. Et alors que 'Abd al-Ra'ûf évoque, on l'a vu, la discipline, l'esprit collectif, la valeur des Frères pour justifier son engagement, Hammûda insiste sur le fait qu'il fut surtout séduit par le contenu de la doctrine d'al-Bannâ.

En 1944, Hammûda et 'Abd al-Ra'ûf vont se mettre à recruter selon des modalités différentes de celles pratiquées au début par ce dernier. Hammûda, lui, recrute son camarade de promotion, voisin à Kubba, et futur beau-frère, le lieutenant Sacd Tawfîq, et entre en contact avec un ami du lycée, le lieutenant de cavalerie Salâh Khalîfa ${ }^{32}$. cAbd al-Ra'ûf sonde un voisin habitant son quartier, le lieutenant d'artillerie Kamâl al-Dîn Husayn, futur membre du $\mathrm{CCR}^{33}$. Habiter le même quartier, c'est emprunter les mêmes moyens de communication - le tramway dans le cas de Kamâl al-Dîn Husayn et de cAbd al-Ra'ûf - souvent aux mêmes heures, et l'on finit par se connaître. Enfin, Salâh Khalîfa recrute, fin 1944, le lieutenant de cavalerie Khâlid Muhyî al-Dîn (futur membre du $\mathrm{CCR})^{34}$. Ces sept officiers (Nâsir compris) constitueront une première cellule, dont le statut est ambigu: est-elle une cellule d'officiers Frères? C'est ce que nous allons déterminer.

La première cellule «Frères musulmans »?

14 Mentionnons d'abord la version de Nâsir lui-même, version erronnée, comme nous l'avons dit: «J'avais de nombreux contacts avec les Frères musulmans, mais je n'étais pas membre de ce mouvement. Je pus ressentir la puissance de leur chef Hasan alBannâ, mais je fus confronté à des difficultés d'ordre religieux; les agissements des Frères exprimaient une forme de fanatisme religieux : or je ne voulais ni renier ma foi ni voir mon pays gouverné par une faction fanatique. $»^{35}$ et $^{36} \mathrm{Il}$ existe plusieurs variantes contradictoires de cette version. Dans l'une d'elles, Nâsir précise que les "Officiers libres » refusèrent explicitement de faire partie des Frères ${ }^{37}$. La contradiction entre ces variantes provient d'une confusion sur la date de naissance du mouvement des Officiers libres. Ce mouvement a été fondé en 1949 et a effectivement refusé de faire partie des Frères. Quoi qu'il en soit, la thèse commune à toutes ces versions est fausse. Du vivant de Hasan al-Bannâ, de 1944 à 1948, Nâsir fut non seulement membre des Frères, mais aussi (dès 1946) de leur branche militaire, l'organisme secret: son témoignage est contredit tant par ses adversaires ('Abd al-Ra'ûf, Hammûda) que par ses partisans (cUkâsha, 


$$
\text { situer son adhésion en 1942, au moment où il fit la connaissance de 'Abd al-Ra'ûf } \mathrm{f}^{38} \text {. }
$$
Cette version, peu crédible, est implicitement démentie par les protagonistes.

cquis, il faut déterminer la date de l'adhésion, son «statut » (" conditionnelle » ou non) et si elle fut enthousiaste, idéologique ou tactique. Nous disposons de plusieurs témoignages des acteurs, à la fois contradictoires et complémentaires. Leur intérêt vient de leur crédibilité : à une exception près, portant sur un point, aucun d'eux n'est entaché de mensonges ou d'erreurs explicites. Les quelques divergences s'expliquent, en règle générale, par la mauvaise qualité de la circulation de l'information, par la confusion, volontaire ou non, des "statuts" - la première cellule est-elle une cellule Frère ? - et de la chronologie - l'on commence un récit à une date et on ne donne pas celles correspondant aux développements ultérieurs - au pis par des omissions volontaires.

'Abd al-Muncim 'Abd al-Ra'ûf

17 Nous reproduisons ici le texte de ses mémoires ${ }^{39}$, en annexe desquelles, il a ajouté ${ }^{40}$ le texte de sa déposition devant la commission de rédaction de l'histoire de la révolution (RHR) et le texte de ses dépositions après son arrestation de 1954 (PFM) ${ }^{41}$, qui présentent quelques variantes. La différence la plus importante est qu'il affirme dans la première déposition ${ }^{42}$ et dans la troisième $\mathrm{e}^{43}$ avoir adhéré aux Frères en 1943, alors que dans le texte qui suit, il parle de 1942 . Tout ${ }^{44}$, notamment les mémoires de Sâdât ${ }^{45}$, indique que la seconde date est la bonne. Nous reproduisons entre parenthèses les précisions utiles apportées par les annexes :

«Je réussis, en octobre 1942, à inviter un officier du $3^{\mathrm{e}}$ bataillon à venir assister au cours du mardi au siège des Frères. C'était le capitaine Gamal 'Abd al-Nâsir Husayn [suivent des détails sur le recrutement des cinq autres officiers]. (En 1943, je le présentai à Mahmûd Labîb, secrétaire général des Frères, et nous nous rencontrâmes tous les trois au salon de thé du zoo, et parlâmes de religion, de la patrie) ${ }^{46}$. En 1944, nos effectifs se complétèrent, nous fûmes sept [iktamala cadaduna $s a b c a]$. Nous nous réunissions une fois par semaine, au domicile d'un tel une fois, chez tel autre une autre, etc. Mahmûd Labîb n'était pas rarement absent. Nos entretiens portaient sur la faiblesse en armement de l'armée, sur les agissements dévergondés de Fârûq, sur l'escalade des actions sionistes contre les Palestiniens, sur l'empressement des partis à briguer le pouvoir, et sur les meilleurs moyens de renforcer nos cellules au sein de l'armée. Nous avions convenu de payer une cotisation mensuelle de 50 piastres, et de constituer une bibliothèque islamique. L'argent était géré par Labîb et la bibliothèque par Hammûda. Tous les mardis, nous nous rencontrions [au siège central des Frères] pour écouter l'opinion des Frères sur les questions d'actualité ou pour assister à une conférence politique, économique ou sociale, au milieu des slogans des Frères, qui bouleversent tout musulman. Nous allions et revenions de la leçon du mardi séparément. Nos cellules au sein de l'armée se multiplièrent: en 1946 (...), le commandant Labîb nous demanda de créer une organisation militaire pour les Jeunes Frères et de les initier aux maniements des armes et aux techniques de la guérilla. Labîb déclara : "Si vous voulez participer avec nous par vos efforts, il est nécessaire de prêter serment, de signer une promesse et une charte." Nous acceptâmes tous. (...) Au début de 1946, nous sept [les sept membres de la première cellule. Par ailleurs, selon les autres témoignages, cette adhésion a lieu après les manifestations estudiantines de février], nous nous rendîmes (en civil) au siège central des "Frères", montâmes au premier étage (...). [Suivent les détails de la cérémonie d'adhésion à l'organisme secret des Frères, tels que les a par exemple rapportés Mitchell $\left.{ }^{47}\right]$. Après avoir prêté individuellement allégeance, nous retournâmes dans la pièce où cette cérémonie 
avait eu lieu, et nous rencontrâmes un homme qui se présenta à nous : 'Abd alRahmân al-Sinadî, qui affirma présider l'organisme secret des Frères, organisation armée comprenant des hommes qui s'étaient donnés à Dieu, tous prêts à mourir pour la Justice, la Vérité et la Liberté. »

Des remarques s'imposent, pour circonscrire quelques problèmes. Comme on le voit, les précisions et omissions chronologiques sont rares, mais cruciales. Quand 'Abd al-Ra'ûf dit que les sept officiers furent approchés en 1944, il a probablement raison. Mais la date de la première réunion collective pose problème : Hammûda ${ }^{48}$ la situe en janvier 1944. 'Abd al-Ra'ûf aussi situe implicitement en 1944 le début des activités et la première rencontre entre Nâsir et Labîb en 1943. Sur ce point, ces deux témoignages semblent douteux : celui de 'Abd al-Ra'ûf est imprécis, puisqu'il dit seulement qu'ils furent sept officiers en 1944, et celui de Husayn Hammûda est peu plausible ${ }^{49}$. Ils sont d'ailleurs contredits par les témoignages de Kamâl al-Dîn Husayn ${ }^{50}$ et de Khâlid Muhyî al-Dîn ${ }^{51}$, qui situent tous deux le début des activités en 1945. Et il ressort de la version de Muhyî al-Dîn que cette première réunion n'eut certainement pas lieu avant décembre 1944 au plus tôt, et plus probablement pas avant février 1945 : en effet, il ne fait la connaissance de Nâsir qu'à cette époque (décembre), et pas dans une réunion. Il ne fait la connaissance de Lâbib qu'après celle de Nâsir, et, encore une fois, pas dans une réunion. Il ne revoit - fortuitement - Nâsir que 45 jours après, à l'occasion d'un match de boxe. Il ne date pas les premières réunions, mais elles interviennent après (infra). Par ailleurs, 'Abd al-Ra'ûf situe la date de l'adhésion à l'organisme secret, mais omet de préciser le "statut " des réunions précédentes de la première cellule et celui des cellules annexes. Y eut-il adhésion formelle aux Frères avant 1946, en 1945 ? ${ }^{\mathrm{C}} \mathrm{Abd}$ al-Ra'ûf dit que Labîb assistait aux réunions de 1945. Le fait est à « double tranchant »: il peut vouloir dire que la cellule est «Frère", mais aussi que ses membres ne sont pas encore acquis à la cause, qu'il reste encore à les convaincre. Les réunions hebdomadaires et la cotisation indiquent l'existence d'une organisation, mais non son affiliation. La constitution d'une bibliothèque islamique est un signe moins ambigu. 'Abd al-Ra'ûf passe sous silence les réticences des autres : or nous sommes sûrs de leur réalité. Il laisse entendre que toutes les cellules créées étaient affiliées aux Frères : or ceci semble explicitement démenti par ' ${ }^{\mathrm{C}}$ kâsha et Husayn al-Shâf $\mathrm{c}^{\hat{5}}{ }^{52}$. Le premier indique que l'existence de sa cellule, celle de Nâsir, qui date de l'été 1945, précède l'adhésion aux Frères, et que cette adhésion fut négociée et conditionnelle (cf. infra). Le second nie toute adhésion formelle aux Frères. Amîn Huwaydî, autre témoin crédible, nie aussi avoir fait partie des Frères ${ }^{53}:$ or il était membre d'une cellule et son nom est mentionné par 'A Abd al-Ra'ûf. Celui-ci reconnaît ailleurs qu'une partie des membres des cellules ne prêtèrent pas allégeance aux Frères ${ }^{54}$. Enfin, les noms qu'il mentionne attirent l'attention : n'y figurent ni 'Âmir ni 'Ukâsha, qui faisaient partie de la cellule personnelle de Nâsir. Oubli curieux, puisqu'il insiste sur le nombre de futurs Officiers libres ayant, selon lui, adhéré à l'époque aux Frères. Oubli ? Ou Nâsir, très secret, aurait-il réussi à sauvegarder l'indépendance de sa cellule et à empêcher tout contact le « court-circuitant»?

Khâlid Muhyî al-Dîn

De Muhyî al-Dîn, nous utilisons deux témoignages : ses Mémoires et sa « confession » à Ghâlî Shukrî̀ ${ }^{55}$. Le texte que nous citons provient de ses Mémoires, les ajouts ou variantes significatives de l'autre texte seront mis entre parenthèses.

«Nous étions fin 1944 (décembre). Nous étions tous embarrassés et hésitants,

cherchant une voie pour nous et pour l'Égypte. Un jour, 'Abd al-Ra'ûf passa me voir 
et me proposa de visiter un officier partageant les mêmes soucis (...) : Gamâl cAbd al-Nâsir. Ce fut notre première rencontre. Peu après, ' $A b d$ al-Ra'ûf me proposa de me présenter à un autre officier; nous allâmes (...) au zoo, où je rencontrai le commandant Mahmûd Labîb, dont je sus après qu'il était le responsable de l'aile militaire des Frères. J'allai au premier rendez-vous avec cUthmân Fawzî [futur Officier libre, diplomate et marxiste]. Lâbib aborda, prudemment et sans se presser, le sujet de la religion. Sachant que notre préoccupation centrale était la cause nationale, il ne cessa d'en parler, mais avec une empreinte, un parfum religieux. [Comprendre: d'un point de vue et en utilisant une terminologie islamiques]. J'insistai pour lui "extraire" des réponses précises aux questions qui me préoccupaient : la patrie, comment la libérer et avec quels moyens? Quelle attitude adopter face aux négociations? Il répondait intelligemment et prudemment : il ne voulait pas nous aliéner en débitant les réponses traditionnelles des Frères [qui évitaient à l'époque une confrontation avec les Britanniques]. Il disait que l'Égypte serait libérée par ses fils, que les jeunes des forces armées sont notre force de frappe, etc.. [Suit un développement sur les réactions négatives de 'U. Fawzî]. Quant à moi, j'étais heureux (...), je pensais que le mouvement islamiste (al ittijâh al-islâmî) pouvait inculquer aux jeunes l'esprit de sacrifice. (...) Je continuai à rencontrer Labîb ; puis, une fois, Nâsir se joignit à nous. En un mot, 'Abd al-Ra'ûf me présenta à Gamâl et nous rencontrâmes individuellement Labîb. Commença alors une drôle de relation avec les Frères. Se constitua un groupe militaire comprenant de nombreux officiers [50, laisse entendre Hammûda ; 100, selon Tucayma ${ }^{56}$ ]. On ne se rencontrait plus en des lieux publics, mais à domicile : chez Magdî Hasanayn, par exemple, ou chez Ahmad Mazhar. Assistaient à ces rencontres "Frères" (liqâacât ikhwâniyya) Nâsir, K. Husayn, H. Hammûda, H. al-Shâfcî, Sacd Tawfîq, Salâh Khalîfa, al-Bughdâdî, Hasan Ibrâhîm [à l'exception du cavalier et futur acteur de cinéma Mazhar et de Salâh Khalîfa, tous sont des futurs Officiers libres]. Les relations de ce groupe avec les Frères étaient délicates : brusquement, les Frères s'étaient trouvés face à une mine d'officiers prêts à faire n'importe quoi pour la patrie. Mais ces officiers n'avaient pas le même degré d'allégeance aux Frères. Par exemple, Salâh Khalîfa et Husayn Hammûda étaient totalement Frères (qalban wa-qâliban). Les autres n'étaient que des éléments à la recherche d'une voie. Nous n'étions pas contre les Frères, mais avec eux, mais pas complètement avec eux. Par exemple, Nâsir avait la conviction que les Frères voulaient nous exploiter en tant qu'officiers, pour qu'on soit un instrument en leurs mains, leur conférant, par le biais d'une influence dans l'armée, un poids et un statut politique; mais qu'ils ne feraient rien pour la cause patriotique. Gamâl, dans les réunions, posait la même question avec insistance: vous dites que vous comptez un demi-million d'adhérents et 4000 sections; pourquoi ne pas commencer des opérations frappant l'occupant, pourquoi ne pas organiser des manifestations et des mouvements de masse? (Je n'étais pas un membre au sens strict (macnâ harfî) du terme, mais je faisais partie du groupe qui était en contact avec les Frères). J'étais aussi un facteur permanent d'instabilité lors des réunions. 'Uthmân Fawzî me poursuivait avec ses livres et me demandait de m'intéresser aux problèmes sociaux. Il semble qu'il était devenu un membre des mouvements communistes, car il me prêta un livre traduit en arabe L'économie est le moteur de l'histoire, de Garaudy. En lisant ce livre, je découvrais plusieurs réponses se succédant et faisais le lien entre l'Égypte et les Égyptiens, la libération de la patrie et celle du citoyen (...). Je commençai à harceler Labîb dans nos réunions : quel est le programme des Frères? Il répondait : la sharî ${ }^{c} a$. Je disais que nous étions tous musulmans, que nous croyions tous en la sharî‘ $a$, mais que je voulais savoir avec précision ce que nous ferions pour libérer la patrie, si nous mènerions une lutte armée ou si nous accepterions le principe des négociations, ce que nous ferions pour le peuple (...) ; il évitait de répondre et je ne cessai de l'harceler. Il finit par faire venir Hasan al-Bannâ. Lorsque commença la rencontre, Nâsir et moi exposâmes nos opinions. Il parla, et nous fit calmement et 
intelligemment comprendre que le mouvement nous accordait un traitement spécial et qu'il n'exigeait pas de nous la complète allégeance qu'il exigeait des membres "normaux" (civils); il déclara: nous, les Frères, sommes une vaste maison, qui peut accueillir tout musulman, quelle que soit la porte qu'il choisisse ; celui qui cherche du soufisme en trouvera chez nous, celui qui veut approfondir sa compréhension de la religion trouvera en nous des personnes prêtes (à l'aider), celui qui veut faire du sport ou le scout en trouvera chez nous, celui qui veut la lutte armée la trouvera chez nous. Vous venez à nous pour la cause patriotique. Bienvenue! Nous discutâmes, il était patient, ouvert et tolérant. J'insistai pour l'élaboration d'un programme (...). Il répondit: "si je prépare un programme, j'attirerai le contentement des uns et le mécontentement des autres, je gagnerai des appuis et en perdrai d'autres. Je ne le veux pas." Les rencontres avec al-Bannâ se multiplièrent. Il avait beaucoup d'arguments, mais ils n'étaient ni suffisants ni convaincants pour la majorité d'entre nous. Nâsir demeura soupçonneux, pensant que les Frères voulaient utiliser un groupe d'officiers pour atteindre leurs propres objectifs. (...) Au cours des discussions, j'adoptai de plus en plus une attitude de gauche et j'étais à contre-courant, un trouble-fête dans un groupe supposé dépendre des Frères musulmans. Finalement, al-Bannâ tenta de nous lier plus étroitement aux Frères; il fut décidé que Gamâl et moi serions membres de l'organisme secret, peut-être parce que nous étions les plus efficaces et les plus influents au sein du mouvement: s'il nous gagnait à sa cause, il emportait l'adhésion de tout le groupe. Peut-être aussi parce que nous parlions beaucoup, Nâsir et moi, de la cause patriotique. [notons que la version de Hammûda ${ }^{57}$ est légèrement différente et probablement plus précise : après la répression, à coups de feu, des grandes manifestations estudiantines du début février 1946, qui se solda par plusieurs morts, les officiers affirmèrent à Labîb qu'il était nécessaire d'armer les jeunes Frères musulmans, d'organiser des cellules et de préparer une guérilla contre les forces d'occupation. Celui-ci répondit que si les officiers voulaient collaborer avec les Frères dans ce domaine, il fallait prêter serment et faire une promesse solennelle]. Il s'imaginait peut-être qu'en nous donnant l'occasion de l'action armée et de la formation militaire de jeunes, il satisferait notre engagement patriotique. [Suit une description de la prestation de serment, semblable à celle de 'Abd al-Ra'ûf et de Mitchell]. Ils nous prirent ensuite pour nous initier au maniement des armes, près de Hulwân. Bien sûr, nous étions plus compétents que nos instructeurs. Nâsir semblait énervé et nous nous sentions de plus en plus éloignés des Frères (...) »

Tharwat ' Ukâsha

Tharwat ${ }^{\mathrm{C}} \mathrm{Ukâsha}{ }^{58}$ :

«À l'École de guerre, des liens nous unirent, Nâsir, Âmir et moi, pour devenir une amitié intime et une communauté de sentiment patriotique (...). Nous étions des jeunes cherchant un moyen (wasîla) nous permettant d'atteindre nos objectifs. Nous décidâmes d'entrer en contact avec les Frères musulmans, dont nous supposions qu'ils étaient désintéressés dans leur prédication. Nâsir, parlant en notre nom, se mit en contact avec un collègue valeureux, le regretté 'Abd al-Ra'ûf, qui nous avait précédés sur cette voie, pour savoir sur quelles bases se ferait l'adhésion aux Frères. Dès le départ, les divergences apparurent sur un problème central : cAbd al-Ra'ûf estimait que l'adhésion devait être inconditionnelle et totale, et nous souhaitions que ceux d'entre nous qui rejoindraient leurs rangs, conservent, au sein $\mathrm{du}$ mouvement des Frères, une entité indépendante. À la fin, les Frères acceptèrent nos vues: les officiers furent indépendants. Des cellules furent constituées, dont les affaires étaient gérées par un comité composé de Nâsir, cAbd al-Ra'ûf, Khâlid Muhyî al-Dîn, Kamâl al-Dîn Husayn, Salâh Khalîfa et d'autres, sans oublier Mahmûd Labîb, qui était l'intermédiaire reliant le Guide suprême (c'était le titre que s'était attribué le regretté Hasan al-Bannâ), le comité et les cellules (...). Ma cellule était composée de Nâsir, Âmir, Hasan Ibrâhîm, Khâlid Muhyî al-Dîn et d'autres. Il y avait des 
réunions hebdomadaires pour examiner la situation et nous assistions aussi au laïus du mardi d'al-Bannâ, qui enflammait notre enthousiasme. Nous le visitions de temps à autre et échangions nos opinions. Les cellules étaient secrètes. Le membre d'une cellule ne pouvait savoir quels étaient les membres des autres cellules, sauf s'il devinait telle ou telle chose. Incontestablement, les Frères étaient l'école qui forma un nombre non négligeable de futurs Officiers libres. »

Husayn Al-Shâfcî̀

21 L'interview accordée par Husayn al-Shâfcî (futur membre du CCR) à Salâh al-Imâm ${ }^{59}$ est particulièrement intéressante, car elle est une critique sévère, et quelquefois injuste, des Frères, émanant d'un officier idéologiquement très proche d'eux. Nous l'examinerons plus loin en détail; contentons-nous de donner ici sa version des événements :

Q - Qui, parmi les dirigeants de la Révolution, était membre des Frères?

$\mathrm{R}$ - Personne. Aucun membre du CCR n'avait de contact avec les Frères. Nos contacts avec eux passaient par le commandant Lâbib, délégué des Frères et responsable de leur activité au sein de l'armée. Mais nous éprouvions de la sympathie (ta'âtuf) pour eux.

Q - Les Frères affirment que Mahmûd Labîb a fondé le mouvement des Officiers libres, en 1942. Cette version est-elle exacte ? Quel est le rôle précis de Labîb?

$\mathrm{R}$ - Le commandant Labîb (...) était un de mes plus chers amis. Je cherchai sa compagnie, qui me mettait à l'aise et me rendait serein. Chez les cavaliers, nous étions une dizaine d'officiers se réunissant chez moi tous les lundis, en la présence de Labîb, à partir de 1946. À ce moment, je dirigeais l'École de cavalerie. Il n'était pas tant là pour nous inviter à adhérer aux Frères, que pour instaurer une certaine sympathie entre les groupes d'officiers (et les Frères), d'une part, et pour puiser des informations sur ce qui se passait au sein de l'armée, de l'autre (...). Il écoutait plus qu'il ne parlait. Il y avait des officiers membres des Frères, mais aucun membre du CCR n'en faisait partie. Dire qu'il a fondé les Officiers libres est inadmissible (...). Il était l'intermédiaire entre les Frères et quelques officiers, pour instaurer des relations de sympathie. Le hasard a voulu que plusieurs membres du CCR soient en contact avec Labîb.

Q - Certains affirment que vous, Kamâl Husayn, voire Nâsir lui-même, étaient membres des Frères. Est-ce exact?

$\mathrm{R}$ - Distinguons sympathie et adhésion. Il y avait effectivement des officiers membres actifs des Frères. Tous ceux que vous mentionnez étaient seulement des sympathisants, comme d'ailleurs beaucoup de monde à l'époque, avant que n'apparaisse l'esprit de fanatisme et de repli sur soi, qui a fini par aboutir aujourd'hui à : soit tu es membre des Frères, soit tu n'es pas musulman [il est intéressant de noter que dès 1942, al-Bannâ mettait en garde des partisans contre la tentation de désigner autrui comme apostat ce qui veut dire que la question se posait cf. supra.]

Kamâl al-Dîn Husayn

Au cours de plusieurs interviews, Kamâl al-Dîn Husayn s'est brièvement expliqué sur la relation entre les officiers et les Frères musulmans. Nous citerons ici les interviews qu'il a accordées aux journalistes Mahmûd Fawzî̀ ${ }^{60}$ et Târiq Habîb. À une question de Fawzî, il a notamment répondu :

«Oui, j’ai rencontré Mahmûd Labîb, secrétaire général des Frères, au domicile de Nâsir, 'Abd al-Muncim 'Abd al-Ra'ûf m'avait présenté à ce dernier. Il parlait beaucoup de lui. Puis 'Abd al-Ra'ûf finit par me le présenter. Plus tard, après 1948 et l'assassinat de Nuqrâshî, nous décidâmes de séparer l'armée [comprendre: les activistes militaires] des Frères. Dans le quartier de Salîbiyya, Nâsir et moi avions prêté serment, sur le Coran, devant un des Frères musulmans - je ne sais si c'était al-Sinadi ou un autre -, nous avons prêté serment (d'œuvrer) pour l'islam. Les 
Fréristes [al-ikhwâniyyûn, au lieu de al-ikhwân, Frères. La nuance est une accusation de dogmatisme, et donc de sectarisme] disent : vous avez juré allégeance aux Frères. Je réponds : Nous avons prêté serment d'allégeance à l'islam. Les militaires sont censés être loin de tout courant ou de tout groupe, quel qu'il soit. »

Avec Târiq Habîb, il a été plus disert sur les premiers contacts avec les Frères :

«J'ai toujours été musulman et dévôt. À l'école primaire, j'avais eu, en première année, le prix de religion. Quand j'étais étudiant à l'université [avant son admission à l'Académie militaire, donc probablement en 1937-1938, un ami m'emmena visiter le siège de l'assemblée des Frères musulmans, au-dessus de l'hôtel du parlement à 'Ataba. Plus tard, j'assistai, de temps en temps, à leurs réunions surtout après qu'ils eurent déménagé à Hilmiyya. Puis il y eut un lien avec eux, à l'époque où je prenais le tramway avec 'Abd al-Muncim 'Abd al-Ra'ûf. On restait souvent longtemps ensemble et les occasions de parler ne manquaient pas (...). On parlait de tout. Il sentit mon patriotisme, je sentis le sien (...). Un jour, il me dit : viens donc, nous organisons des réunions. Nous allâmes ensemble. Où ? Chez Gamâl cAbd al-Nâsir. Je trouvai ce dernier en compagnie d'un monsieur qui s'appelait Mahmûd Labîb, qui était lui aussi en contact avec les Frères ou, plutôt, qui était le délégué des Frères (...). C'était un homme agréable, à la conversation passionnante, qui parlait de la religion, de l'islam, de l'utilité de l'islam pour la réforme de la société (islâh almujtama ${ }^{\prime}$ ), qui parlait aussi de l'armée, du patriotisme, de la nécessité de se débarrasser des Anglais, bref des sujets dont nous parlions. Se mirent en place les contacts avec les officiers qui traitèrent avec ce courant, et nous nous réunissions une fois par semaine, chez l'un des nôtres ; des réunions secrètes, bien sûr. »

Ces témoignages semblent difficiles à concilier. Écartons d'abord le démenti de Shâf $\hat{\imath}$ sur l'ancienne appartenance de membres du CCR aux Frères, qui est per se inexplicable et qui doit être située dans le cadre de la guerre idéologique que se livrent périodiquement nassériens et Frères. Retenons-en que Shâfî nie, pour sa part, avoir fait partie des Frères. Mais même ceci, qui semble plausible, est contesté par plusieurs sources ${ }^{61}$. Shâfî considère peut-être que seule une prestation de serment (une "allégeance", bayca) implique une adhésion. Ceci excepté, tous les témoignages semblent crédibles, de première main, fondés. Le problème est d'expliquer les divergences entre eux. Signalons d'abord que le confident de Nâsir, à l'époque, est Khâlid Muhyî al-Dîn ${ }^{62}$. D'autre part, deux témoins ('Ukâsha et Shâfî) ne font pas partie de la cellule centrale, du noyau dur des sept officiers. Il est donc possible d'expliquer certaines divergences par leur situation périphérique, impliquant qu'ils n'ont pas directement accès à certaines informations. Pour rendre compte de la dissonance de la version de cUkâsha, témoin des plus crédibles, une seule explication est possible : Nâsir ne lui aurait pas immédiatement révélé l'existence d'une cellule centrale, comme il lui aurait au départ caché ses liens avec 'Abd al-Ra'ûf. Sur ce point, la version de 'Ukâshâ s'explique par celle du Frère musulman Salâh Shâdî ${ }^{63}$, qui indique que les Frères reprochaient fréquemment à Nâsir le non-respect par ses recrues des préceptes moraux, et surtout le fait qu'il n'informait pas lesdites recrues de son appartenance aux Frères. D'après lui, Nâsir répondait en expliquant qu'il était « trop tôt " pour cela, pour sauvegarder l'organisation et assurer sa sécurité. cukâsha semble penser que la «base » a nommé le noyau dur. Nâsir l'a-t-il induit en erreur? Ou faut-il comprendre «libre consentement " au lieu de "choix actif ", cUkâsha soulignant l'autonomie par rapport aux Frères? Nous privilégions cette hypothèse. Par ailleurs, se pose le problème de la réalité des réticences de Nâsir, que Khâlid souligne avec force et que 'Ukâsha omet complètement (il ne les situe qu'en 1947-1949). Khâlid est le confident de Nâsir et il semble qu'il soit plus proche de la vérité : en effet, Nâsir, contacté dès 1942, n'adhère 
pas immédiatement aux Frères; quand il sera chargé de recruter des officiers, il choisira des patriotes, sans s'attarder sur leur ferveur religieuse - un reproche en ce sens lui sera fait, rapporte encore Shâdîn. Que Nâsir n'ait jamais été un Frère « doctrinaire » est également illustré par le fait qu'il encouragea à l'époque Muhyî alDîn à garder et à développer ses contacts avec les militaires marxistes et que lui-même écoutait avec "un grand intérêt » tous les autres, quelle que soit leur appartenance idéologique. Khâlid, qui était, répétons-le, très proche de lui à l'époque, affirme qu'il était un patriote qui lisait beaucoup et qui n'avait "pas trouvé de voie précise »65. La version de Muhyî al-Dîn, sur le scepticisme (relatif ?) de Nâsir et son recul par rapport aux thèses et à la pratique des Frères, est indirectement confirmée par celle de l'officier libre Ibrâhîm al-Tahâwî ${ }^{66}$, qui faisait à l'époque (1945-1946) partie des cellules Frères. Il indique qu'en 1946 il suggéra, au cours d'une réunion, un putsch " commun » entre l'armée et les Frères. Après celle-ci, Nâsir l'interpella, pour lui demander s'il était prêt à collaborer à une éventuelle constitution d'une organisation militaire unifiée comprendre : regroupant les divers groupuscules militaires clandestins, quelle que soit leur affiliation politique - et, si nous comprenons bien, indépendante des Frères ; c'est d'ailleurs ainsi que Shâdî comprend l'épisode ${ }^{67}$. Si cette interprétation est la bonne, elle révèle un manque de confiance dans la direction des Frères, et un pragmatisme très peu idéologique $^{68}$. La version de Khâlid Muhyî al-Dîn est surtout confirmée par Husayn Hammûda ${ }^{69}$, qui rapporte que Nâsir s'exclama, fin 1945, au cours d'un dîner chez 'Abd al-Ra'ûf: "Jusqu'à maintenant, je suis incapable de comprendre ce que les Frères veulent exactement des militaires. » Interrogation à laquelle Hammûda répond : « Rien. Ils veulent répandre la doctrine islamique dans les diverses couches de la population (...). Quand ces principes seront majoritaires en Égypte, ils présenteront des revendications au gouvernement égyptien, qui se résument à ce que la Parole de Dieu soit la Constitution de l'Égypte (...)» Hammûda expose ensuite les actions manifestations, désobéissance civile - envisagées par les Frères si le gouvernement auquel seront présentées ces revendications se dérobe. Nâsir, dubitatif, répond : «Ceci prendra beaucoup de temps, sera même peut-être irréalisable, et il ne reconnaît aucun rôle aux officiers de l'armée qui seront commandés et non commandants ». À l'exception de la dernière remarque, les officiers « commandés » - qui a probablement pour objectif de " prouver » que Nâsir est un obsédé de la prise du pouvoir, ce qui nous semble très improbable mais pas impossible en 1945, et qui est très probablement apocryphe, ou citée hors contexte - l'anecdote est plausible, même si elle tend à discréditer Nâsir, et ne rend pas compte de ses priorités : lutter contre la présence militaire britannique, plutôt que d'islamiser lentement la société ${ }^{70}$. Notons enfin que Muhyî al-Dîn, contrairement à Nâsir et à Shâfî, n'évoque pas le problème du «fanatisme» des Frères. Ce qui veut probablement dire qu'il n'entra pas immédiatement en ligne de compte et qu'il ne se posa que plus tard, comme le dit cUkâsha (voir infra suite de son témoignage) et le laisse entendre Shâfî̀, au moment où le cycle des attentats et de la répression commence.

Il ressort du récit de Khâlid Muhyî al-Dîn que l'adhésion aux Frères eut bel et bien lieu avant février 1946, date de l'adhésion à leur organisme secret: dans le courant de l'année 1945, avant la fin de la Seconde Guerre mondiale. Cela n'est pas dit explicitement, mais, commentant sa "dérive " gauchiste, il déclare que ce groupe dépendait des Frères. Sa citation d'al-Bannâ, qui affirme que les Frères n'exigent pas des officiers la même totale allégeance qu'ils attendent des civils, implique qu'il y a une allégeance sui generis. Quand, dans sa confession à Shukrî̀ ${ }^{11}$, il dit qu'il n'était pas 
membre au sens strict du terme, il faut comprendre que les officiers n'étaient pas entièrement convaincus et avaient obtenu une grande autonomie. Le témoignage de cUkâsha, qui laisse entendre que l'adhésion eut lieu à l'automne 1945 ou en hiver de la même année (puisque Nâsir était à l'École de guerre) est moins décisif, car il ne concerne probablement que des membres de la cellule de Nâsir. Le témoignage de Shâf $̂ \hat{~}$ ne les contredit pas véritablement: pour lui de nombreux officiers assistaient aux réunions, par curiosité ou pour toute autre raison, en sachant que celles-ci organisaient une coordination avec les Frères et assister à ces réunions n'impliquait pas une adhésion au mouvement de Hasan al-Bannâ. Cette version est confirmée par Muhsin 'Abd al-Khâliq (futur Officier libre), qui explique que de nombreux officiers, sans adhérer aux Frères, étaient séduits par la personnalité de Mahmûd Labîb et adoraient discuter avec lui, ou lui demander conseil ${ }^{72}$. Ceci explique peut-être pourquoi ${ }^{\mathrm{c}} \mathrm{Abd}$ alRa'ûf oublie cÂmir. Ceci explique aussi le démenti de Huwaydî. Nous verrons que ces témoignages sont confirmés par celui de Labîb, rapporté par Shâdî. La situation qu'ils décrivent suggère que certains officiers fréquentent plusieurs mouvements (et non les seuls Frères) et que la circulation de l'information est défectueuse, même au sein du groupe qui gravite autour de Labîb.

Par contre, Hammûda insiste sur l'aspect organisationnel des cellules ${ }^{73}$. D'après lui, les sept membres de la première cellule centrale créèrent chacun une cellule auxiliaire, comprenant au maximum sept membres, connus de leur seul chef et de Mahmûd Labîb. Il indique que ce dernier assistait aux réunions hebdomadaires de la cellule centrale et à celles, bi-mensuelles, des cellules auxiliaires. Le tableau dépeint par Muhyî al-Dîn et ${ }^{\mathrm{c}} \mathrm{Abd}$ al-Ra'ûf $\mathrm{f}^{74}$ est celui d'un organigramme beaucoup moins rigoureux et secret que ne le laisse entendre Hammûda. Par contre, le témoignage de ${ }^{\text {Ukâsha }}{ }^{75}$ confirme les grandes lignes de celui de Hammûda - sauf sur les points du «secret» et du "cloisonnement", puisque Muhyî al-Dîn et Nâsir, tous deux membres de la cellule centrale, étaient selon lui membres de la même cellule annexe. cukâsha parle aussi de réunions hebdomadaires pour les cellules annexes, mais cela ne vaut peut-être que pour la cellule à laquelle il appartient. En résumé, il semble que Hammûda, soucieux de « délégitimer » les Officiers libres, d'en nier l'originalité et d'établir une filiation entre eux et les «Frères ", ait un peu accentué le caractère structuré des cellules. Mais, même si sa description est exacte, il ne tranche pas le problème de l'adhésion effective des membres des cellules auxiliaires aux Frères.

Pour résumer, il semble qu'une fois acquis le principe d'une autonomie et d'un «traitement spécial» des officiers, on n'ait pas attaché une importance primordiale à la question de la clarification du «statut " des personnes assistant aux réunions ou à celui de celles-ci. Celui qui s'y rendait « collaborait », était, membre ou non des Frères, en contact avec eux. Les Frères, enfin, acceptaient l'adhésion de militaires, même si ceux-ci avaient des réticences idéologiques. L'originalité du traitement réservé aux officiers réside dans l'abandon de la demande de l'adhésion aux thèses des "Frères " comme préalable à l'admission.

Pourquoi les Frères?

Leur adhésion aux Frères, tout comme celle de Nâsir, s'explique par un souci d'«efficacité ", par un préjugé favorable, ou par un malentendu, plutôt que par une adhésion à leur credo. Salâh Shâdî (Frère) a indirectement confirmé ces versions, en rapportant ${ }^{76}$ une confidence de Mahmûd Labîb : 
«En 1946 (...), Labîb m'affirma qu'il estimait que restreindre la prédication des Frères au sein de l'armée aux seuls officiers dont l'allégeance au mouvement ne pouvait être mise en doute, privait ce dernier d'une base très importante d'officiers patriotes (...). Si ces officiers rejoignaient les cellules respectant les règles $d u$ mouvement, ce serait une bonne préparation, leur permettant de comprendre l'action islamique souhaitée dans le cadre de la prédication,et ceci tiendrait lieu (pour ces officiers) de prédication précédant le serment d'allégeance [en clair: plutôt que de recruter les seuls officiers ayant un comportement irréprochable du point de vue de la morale islamique et totalement acquis aux idées des Frères, pas assez nombreux, recrutons également, estime Labîb, les officiers patriotes, et l'exemple que fournira le comportement des Frères qu'ils seront amenés à côtoyer permettra de les "former ", de les initier à l'idée islamique, à "dépasser " le nationalisme]. (...). Je ne vis pas tout de suite le danger de diversification des allégeances (...). Certains resteraient fidèles à ceux qui les avaient enrôlés (...) tandis que d'autres seraient fidèles à l'islam, même si leur chef apostasiait ${ }^{77}(. .$.$) . Nâsir$ profita de l'autorisation de Labîb pour enrôler des officiers qui n'agissaient pas en ayant l'islam pour point de départ (...). Il le faisait d'abord en cachette, aidé en cela par les techniques de recrutement de nouveaux officiers. En effet, il était interdit (aux recruteurs) de dévoiler leur identité islamique [comprendre: Frère] aux officiers invités à rejoindre l'organisation. La couverture utilisée pour leurs activités, pour séduire le cœur des nouveaux officiers était de parler de ce qu'endurait la nation du fait de l'occupation britannique et de la complicité des gouvernements. Pour les prédicateurs sincères, cette couverture n'était pas un moyen de rassembler des officiers pour leur propre compte. »

Efficacité : la tentation de faire partie d'un mouvement social de masse (supposé ?) hostile au pacte politique de compromission avec les Britanniques. Shâdî reprochera aux officiers d'avoir avant tout été impressionnés par la "puissance matérielle » des Frères $^{78}$. Nâsir et Sâdât parlent surtout de la puissance (quwwa) d'al-Bannâa ${ }^{79}$. Le préjugé favorable est double : un préjugé sur la «valeur » individuelle et collective du groupe. Individuellement et collectivement, être Frère, c'est un renoncement ${ }^{80}$ aux intérêts privés, un rapport aux valeurs centrales qui consacre la primauté absolue de celles-ci, et un engagement total et actif pour elles. L'école de l'islam est une école qui vous inculque «l'esprit de sacrifice » de soi et a fortiori des intérêts privés. Être Frère, c'est aussi, aux yeux des militaires, et de nombreux sympathisants, «forclore » le politique, assimilé au factionalisme des partis (ce qui en arabe est un pléonasme) ${ }^{81}$, créateur de divisions artificielles parce que portant sur des questions "secondaires", ou non ontologiques, au profit de la norme et des valeurs centrales. La séduction exercée par les Frères vient aussi du fait qu'ils sont censés ne pas être des politiciens. Là, bien sûr, l'erreur d'appréciation est énorme ${ }^{82}$. Autre préjugé favorable, les Frères et leur intégrité individuelle exemplaire sont un exemple moral et répondent à une attente éthique. De ceci, nous n'en avons, outre le témoignage trop rapide de cUkâsha, qu'une preuve indirecte. Dans un de ses articles après le succès du coup d'État, intitulé "Comment nous avons préparé ce coup d'État ${ }^{83}$, Nâsir a décrit son état d'esprit à la fin de la Seconde Guerre mondiale - c'est-à-dire au moment où il adhère aux Frères : « (en 1946), si nous regardions à l'intérieur, à l'intérieur de l'armée, nous voyions la pourriture, la décadence morale, la lâcheté, l'humiliation, la soumission, les pots-de-vin, la corruption, le vol, l'ignorance (...)». Poser le problème en ces termes (pertinents, d'ailleurs) nous semble de nature à susciter une orientation favorable aux Frères. D'autant plus que ceux-ci sont représentés par deux individualités remarquable, 'Abd al-Ra'ûf et surtout Labîb, qui inspirent tous deux confiance et suscitent l'admiration des jeunes officiers. Enfin, plus profondément, les Frères - c'est un de leurs succès les plus 
remarquables - ont réussi, aux yeux de très larges secteurs de l'opinion publique, à s'approprier le rôle de représentants, voire d'incarnation, de la Foi dans l'espace public, supplantant les 'ulamâ' et les shaykhs soufis. Seules leurs pratiques remettront en cause ce statut.

Le malentendu (ou le différend volontairement «occulté ») vient, très clairement, du fait que la majorité des officiers provient, idéologiquement, quelles que soient leurs futures trajectoires, de la constellation politique Misr al-Fatâh/Parti national et sont les disciples de 'Aziz al-Masrî. Cette constellation, malgré de nombreuses similitudes avec celle des Frères, est radicalement différente, de par sa logique. D'une part, les officiers sont « politiquement » d'abord « patriotes » et nationalistes : la priorité absolue est à la lutte contre les Britanniques. L'islam, avec ses vertus morales et ses capacités mobilisatrices, est, outre la "religion, culture et Weltanschauung » de la nation, l'une des meilleures «voies» (moyens) vers la libération nationale, qui est la «fin». Mais, pour paraphraser Salâh Shâdî̀ ${ }^{84}$, qui le leur reproche, ils n'ont aucun inconvénient à recruter des officiers fréquentant les bars (buvant de l'alcool) et fumant du haschich si ceux-ci sont des patriotes prêts à agir. Le patriotisme doit être distingué des autres vertus. Chose inconcevable ${ }^{85}$ pour la plupart des officiers véritablement Frères, tels ${ }^{\mathrm{c}} \mathrm{Abd}$ alRa'ûf, Hammûda, Sacd Tawfîq, Salâh Khalîfa, soucieux d'islamiser la société et de recruter des musulmans « irréprochables ", de créer un « musulman nouveau ». D'autre part, la place et le statut respectif des « savoirs profanes » et des « savoirs religieux » ne sont pas les mêmes dans les deux constellations. En une approximation rapide, il est possible de dire que si les nationalistes proclament la primauté des "sciences religieuses", en pratique l'autonomie des savoir-faire profanes est largement respectée ${ }^{86}$. Si les Frères sont profondément respectueux des savoir-faire " profanes ", en pratique ceux-ci sont soumis au contrôle de la norme religieuse ou de ses représentants ${ }^{87}$. Pour les officiers nationalistes, un Frère est un musulman valeureux, donc partageant ce désir de lutte anti-colonialiste: c'est d'ailleurs le cas de cAbd alRa'ûf, de Hammûda, de Labîb et d'al-Bannâ. Mais ce dernier est un politique, soucieux de prendre le pouvoir, de ne pas effrayer immédiatement les élites et les Anglais, et de "brasser large » : la lutte anti-britannique n'est pas (toujours) dans son « agenda » de priorités, qui sont politiques et perçues comme politiciennes. Al-Bannâ est à la fois hors du pacte politique et dans ce pacte, hors du et dans le système politique : il a deux fers au feu et il peut renoncer temporairement aux revendications nationalistes pour des gains immédiats (accès au papier-journal à des prix subventionnés, par exemple ${ }^{88}{ }^{89}$ ). La dimension politique du mouvement, Nâsir la perçoit très vite. Le fait même qu'al-Bannâ accepte les conditions des officiers semble susciter sa méfiance. Son diagnostic est lucide : les «Frères ne feront rien »- du moins pas dans l'immédiat, sans avoir l'excuse de la faiblesse ou de la marginalité. Or, pour Nâsir, la véritable et bonne politique, c'est le «faire» au service de normes ontologico-éthique, patriotique et religieuse. Et sa conclusion est que la norme est, chez les Frères, au service du politique, des gains immédiats de certaines factions et non l'inverse. C'est injuste, parce qu'il ne voit pas ou oublie que leur conception de la norme, et des priorités, est différente. Une critique plus justifiée est celle qui reproche aux Frères leurs priorités, l'islamisation passant avant la libération.

31 Ceci dit, il faut reconnaître que certaines décisions d'al-Bannâ sont, même de son propre point de vue, d'énormes erreurs, comme celles de se démarquer en 1946 de l'agitation nationaliste menée par le Wafd et les marxistes. Même certains officiers 
(Kamâl al-Dîn Husayn ou Husayn al-Shâfî), plus proches, par idéologie, des Frères musulmans que du Parti national, quitteront en 1948-1949 les Frères avec Nâsir. Husayn al-Shâfî a pu affirmer qu'« un musulman n'appuie la prédication pour l'Islam qu'après s'être assuré : est-elle sincère ? Est-elle prête au sacrifice et au don? Ce n'était pas le cas des Frères. $\|^{90}$ L'accusation (injuste dans sa formulation ${ }^{91}$ ) déduit la perversité entre autres à partir de plusieurs énormes erreurs de calcul du Guide suprême, se méprenant totalement sur l'état d'esprit de la population.

Il convient de préciser le sens de « d'abord patriotes » et ceci nous amène à aborder la question de l'adhésion au credo des Frères Il faut voir qu'entre "patriotisme " et " esprit religieux ", il n'y a pas, pour la population que nous étudions, de jeu à somme nulle. Le patriotisme, le nationalisme, la nation ne sont pas, au moins aux yeux de nos acteurs $^{92}$, des valeurs « importées » ou « laïques ». Elles sont aussi authentiques que la fidélité à l'islam. Peu importent les conceptualisations théoriques des intellectuels des divers camps (laïques, réformistes, salafistes, etc.). Il existe une sorte de "sagesse conventionnelle ", d'état d'esprit propre au moins aux membres des classes moyennes, nouvelles ou non, qui sont à la fois religieux et patriotiques, état d'esprit qui permet de donner de nombreuses réponses aux problèmes de l'actualité et autorise l'établissement de nombreuses articulations entre patriotisme et islam, dont l'étude déborderait le cadre de ce travail. Néanmoins, en 1945, deux types d'approche peuvent être distinguées : a) pour certains, la société n'a pas à être réislamisée, soit parce qu'elle est musulmane et qu'il y a plus urgent (l'occupation britannique), soit parce qu'on n'est pas, tout en adhérant à ce credo, prêt à imposer la conformité des croyances et des pratiques à une société. Ce refus peut être de l'amoralisme, comme l'estiment les Frères, mais peut aussi être un jugement sur le caractère souhaitable, ou sur la viabilité "dans l'absolu », ou encore sur l'opportunité conjoncturelle, d'une telle approche; b) pour d'autres, l'islam est affaibli par le comportement des musulmans ${ }^{93}$. Une adhésion stricte à ses préceptes, tels qu'ils sont expliqués par la (les) doctrine (s) classique (s), ainsi qu'un engagement total dans la «voie de Dieu » règleront tous les problèmes ou susciteront l'état d'esprit et le cadre structurel objectif permettant de le faire. Les futurs Officiers libres oscillent entre ces deux types d'approche, mais finiront, en 1949, par opter pour la première.

Ceci affirmé, il est possible d'ébaucher, à partir des différents récits, une reconstruction de la perception que les acteurs avaient, en 1945, des Frères, et du message d'al-Bannâ. L'on reconnait à al-Bannâ d'avoir profondément renouvelé la prédication " orale » et populaire. Pour Shâdî, «c'était un shaykh qui, contrairement aux autres, ne parlait pas de ce qui pouvait vicier les ablutions, mais de la réalité profonde de l'islam (jawhar) ${ }^{94}$. Hammûda et Sâdât ${ }^{95}$ parlent de "compréhension éclairée»: par cela, il faut comprendre une volonté de lutter contre les superstitions populaires et certaines formes jugées dégénérées de soufisme ${ }^{96}$, et d'inscrire l'islam dans le monde de la praxis. Son éventuelle originalité doctrinale n'était pas au centre des préoccupations des Officiers, ni de Shâdî, ni de Kamâl, contrairement à celles, par exemple, de Mahmûd 'Abd al-Halîm ${ }^{97}$. Nous pouvons affirmer qu'elle semble n'avoir frappé personne des susnommés, (Shâdî exceptés8 ?). Aucun ne mentionne un éventuel combat contre la laïcité, ni ne se soucie de poser les questions en termes d'opposition (éventuellement à dépasser) entre réformistes et salafites ou entre soufis et fondamentalistes sunnites. Certains, dont 'Abd al-Muncim 'Abd al-Ra'ûf, cUkâshâ, Muhyî al-Dîn, ne mentionnent même pas le credo des Frères comme facteur ayant entraîné leur adhésion. Car ce credo 
est perçu comme étant l'islam, qui est la foi commune à tous, et la sharî́a, dont l'excellence (au moins celle de ses fondements) est reconnue par tous ${ }^{99}$. Ce credo ne justifie pas seul, l'adhésion à un groupe particulier. La version qu'al-Bannâ en donne ${ }^{100}$ reflète l'opinion grosso modo des nouvelles classes moyennes, mais pas seulement de celles-ci. Elle s'adresse d'abord à une clientèle pieuse, pratiquante, soucieuse de vivre sa foi et de la servir, mais peu passionnée par, ou ne voulant pas être paralysée par les querelles d'école, ou par le conflit entre le soufisme et le figh sunnite ${ }^{101}$. En osant une formulation rapide, nous dirions que le credo d'al-Bannâ est largement traditionnel et qu'il pense que la rationalisation de la religion passe par une "épuration " des superstitions, permettant une meilleure mise en valeur des fondements véritables de l'islam, tels qu'ils sont révélés par le Coran et par la Sunna. Cette rationalisation n'exige pas, sauf peut-être sur quelques points, une relecture radicalement nouvelle du dogme. " Nous apprîmes que la religion est puisée dans les textes (al dîn yu'khadh min nusûsi-hi), que toute nouveauté (mahdatha) est invention (bidca) ; toute invention est égarement » (dalâla) ${ }^{102}$. Cette invention vise autant la laïcité, les formes extrêmes du réformisme, d'une part, que le soufisme et le culte des saints, de l'autre. Al-Bannâ, qui a été soufi dans sa jeunesse, reconnaît les vertus pédagogiques d'éducation de l'âme du soufisme, tout en rejetant les "excès" et les "déformations" induites par celui-ci ${ }^{103}$. La nouveauté apportée par al-Bannâ, telle que la voient nos acteurs, n'est pas tant ce credo, auquel les officiers adhèrent " globalement ", ou le fait d'insister sur sa primauté absolue sur tous les autres aspects de la vie, que d'affirmer que cette primauté doit se traduire par une islamisation de tous lesdits aspects, et surtout que doivent se mettre en place des structures d'action à cette fin, et d'insister sur les valeurs «volontaristes » : force, esprit de sacrifice, jihâd, fidélité, volonté de puissance, autoéducation. Ces valeurs sont d'autant plus puissantes et novatrices qu'elles interviennent dans un champ religieux où la large diffusion « des excès » du soufisme et du culte des saints est souvent perçue, à tort ou à raison, comme la cause, directe ou non, d'une passivité et d'un fatalisme supposés - et bien sûr déplorés.

Par exemple, Ahmad 'Âdil Kamâl estime que l'originalité des Frères réside dans le fait qu'ils prennent au sérieux l'obligation de jihâ $d^{104}$. Une revue Frère titre: «Nous ne voulons en notre sein que des croyants acceptant le fardeau et les obligations du Jihâd." Salâh Shâdî explique qu'al-Bannâ a bien compris l'importance de la "force " (puissance), qui doit être un objectif per se (matlab maqsûd li-dhâtihi) ${ }^{105}$. Hasan Dûh affirme que les Frères ne pensaient qu'au jihâd, à mourir pour Dieu ${ }^{106}{ }^{107}$. L'originalité d'al-Bannâ, ce n'est pas son credo : c'est le statut assigné à ce credo et la grande place reconnue au "faire au service de la norme ", dans sa conception. Notre impression est que le Guide suprême en avait lui-même très nettement conscience. Quand des amis 'ulamâ' lui demandèrent d'écrire des ouvrages doctrinaux pour exposer ses vues, il répondit en substance que le monde musulman était noyé sous les ouvrages doctrinaux, mais qu'il manquait d'hommes agissant : « le temps que je perdrais à écrire un livre, je préfère l'exploiter à former cent jeunes musulmans, pour que chacun d'eux devienne un livre vivant, parlant, agissant, influant », conclut-il ${ }^{108}$. Mitchell a montré qu'un des thèmes (ou rengaines) favoris d'al-Bannâ était la condamnation des controverses doctrinales, qui avaient mené à un « islam de mots et de phrases plutôt qu'à un islam de foi et d'action $»^{109}$. Les Frères sont des musulmans qui œuvrent pour tels et tels objectifs. Le jihâd est la voie des Frères, dit leur slogan ${ }^{110:}$ qu'il soit traduit par effort ou guerre sainte, peu importe dans ce contexte ${ }^{111}$. Ce qui frappe les auditeurs (Hammûda, Sâdât ${ }^{112}$, par exemple), c'est cette dimension concrète, volontariste, de praxis et 
d'action, que révèlent les discours d'al-Bannâ. Le discours est « éclairé » car il rappelle que l'islam n'est pas seulement prières, jeûne, charité. Il est un guide d'action. Les officiers nationalistes de l'après-guerre "cherchent la voie" (Muhyî al-Dîn ${ }^{113}$ ). Ils veulent agir. Nous espérons avoir réussi à expliquer pourquoi ils s'orientent d'abord vers les Frères, dont, de surcroît, la puissance les impressionne. Néanmoins, la persistance de leur quête intellectuelle très "profane ", philosophique, sociologique, politique (celles de Nâsir, de 'Ukâsha, de Bughdâdi, de Muhyî al-Dîn sont exemplaires ${ }^{114}$ ) montre bien que ce choix ne les satisfait pas entièrement. Par exemple, entre 1945 et 1948, si Muhyî al-Dîn lit des ouvrages marxistes, Nâsir découvre, entre autres, Laski, Bell, Bevan, Nehru ${ }^{115}$. Par ailleurs, cUkâsha reconnaît avoir eu à l'époque des "doutes » en matière de foi, avoir étudié les religions, ainsi que la philosophie japonaise, et n'avoir été " pacifié » que par l'ouvrage d'un psychiatre américain, Henry Link, The Return to Religion, qu'il traduisit en arabe en $1948^{116}$.

La plupart des militaires resteront dans ce mouvement jusqu'en 1949, et le quitteront au plus tard au retour de la guerre de Palestine. Nous ne pouvons, dans ce cadre, étudier en détail la collaboration entre officiers et Frères entre 1945 et 1948. Disons que l'image qui s'en dégage est celle d'un souci de discrétion et d'une concentration sur la création de cellules au sein de l'armée, avec une participation des militaires à la formation des membres de l'organisme secret. Des dispositions furent prises pour garder secrète l'affiliation des Officiers aux Frères ${ }^{117}$. Outre la reconnaissance d'une grande autonomie organisationnelle, les officiers ne se montraient que peu dans les sections des Frères. S'ils assistaient aux cours hebdomadaires d'al-Bannâ, c'était généralement en civil et non en uniforme. Ceux qui adhérèrent à l'organisme secret (la branche armée des Frères, fondée par al-Bannâ en $1940^{118}$ pour "lutter contre les Britanniques, guerroyer contre les ennemis du mouvement et accomplir le devoir du jihâd $»^{119}$ ), suivirent des cours de figh, dispensés par le shaykh Sayyid Sâbiq, un des Frères les plus en vue, délégué par al-Bannâ pour assurer la formation doctrinale des officiers, et qui devint le muftî de l'organisme secret. Le shaykh Sâbiq rédigea des polycopiés de figh à leur intention ${ }^{120}$. Plus tard, ces cours devaient être dispensés à tous les membres, militaires ou non, de l'organisme secret et finirent par être publiés, en trois tomes, sous le titre Figh al-sunna ${ }^{121}$, aujourd'hui un classique. Ils comportent une étude approfondie du jihâd, de son statut dans le Coran et la Sunna, et de son rôle dans l'histoire de l'islam ${ }^{122}$. Il convient en conclusion d'insister sur le fait suivant: quelles que soient les réticences de Nâsir, il est très vite l'un des membres les plus en vue de l'organisation ${ }^{123}$.

La rupture entre Nâsir et les Frères musulmans : le prélude

La guerre de Palestine voit les liens entre Frères et Officiers se distendre. D'une part, les Officiers sont " occupés " ailleurs, avec de lourdes responsabilités. Hammûda ${ }^{124}$ admet que les cellules Frères arrêtent toute activité en 1948, du fait de la guerre. De l'autre, l'escalade de la confrontation entre les autorités et les Frères ${ }^{125}$, culminant avec les assassinats du Premier ministre Mahmûd al-Nuqrâshî et de Hasan al-Bannâ, et le recours de ceux-ci aux attentats et à la violence terroriste contre des Égyptiens, à un moment où le pays est en guerre et où la sécurité intérieure est d'une importance cruciale, choquent plusieurs Officiers. Les Frères apparaissent comme "sectaires", violents, comme un facteur de division. La rupture intervient en 1949, après la mort d'al-Bannâ, assassiné en février par des membres de la police, en réponse à l'assassinat d'al-Nuqrâshî, et peu avant celle de Mahmûd Labîb, terrassé par la maladie à la fin de 
1949, mort au début 1951. Elle est consécutive à - ou incarnée par - un différend entre Nâsir et 'Abd al-Ra'ûf, qui éclate au grand jour et que ni al-Masrî ni d'autres ne réussiront à aplanir. Ce différend illustre le très grand scepticisme de Nâsir vis-à-vis des Frères et se traduit par la décision du futur ra'îs de créer une organisation militaire clandestine, fédérant si possible tous les groupuscules existant, recrutant le plus grand nombre d'officiers, toutes tendances politiques confondues, rassemblés autour d'objectifs nationalistes et faisant passer leur allégeance à cette organisation avant toute autre fidélité. Avant d'étudier cet épisode crucial, rappelons les diverses frictions ayant opposé, entre 1946 et 1948, Frères et officiers (que ces derniers soient de simples sympathisants ou des adhérents), telles qu'elles sont relatées par les témoins et les acteurs et le jugement " global » porté par les officiers ayant adhéré aux Frères, après quelques années de "pratique interne ». Certes, certains des épisodes relatés n'ont d'autres n'auraient dû avoir - qu'un statut anecdotique. Mais ils permettent de restituer, au moins partiellement, « l'atmosphère » de la collaboration entre militaires et Frères et sa lente dégradation, qui aboutit en 1949 à la création de l'organisation des Officiers libres. Ils permettent également de mieux cerner les divergences et les points communs entre les uns et les autres, et de rendre compte de la multitude des parcours individuels, qui viennent s'agréger en un "fait " sociologique majeur, qu'on ne peut expliquer par la simple manipulation exercée par un esprit démoniaque - statut accordé par les Frères à Nâsir.

Le soutien accordé par les Frères à « l'anglophile » gouvernement de Sidqî pasha (fév.déc. 1946), qui fait l'unanimité de la rue contre lui, est scandaleux aux yeux des officiers. Citons Khâlid Muhyî al-Dîn ${ }^{126}$ :

«Les Frères dévoilaient ainsi leur face "politique", ils agissaient en tant que groupe politique et abandonnaient les prétentions à la pureté religieuse. Ils avaient besoin de publier un quotidien et donc de papier, dans un contexte de sévère pénurie. Ils se rapprochèrent de Sidqî et obtinrent en échange les subventions voulues. Ils se prononcèrent contre le comité patriotique des étudiants et des ouvriers [une coalition de wafdistes et de marxistes] et tentèrent de fonder un autre comité, coopérant avec Sidqî. Nous comprîmes qu'ils étaient comme tous les autres politiques, préférant leurs propres intérêts et ceux de leur groupe aux principes qu'ils proclamaient et à l'intérêt national. " Je discutai longuement avec Nâsir de notre relation avec les Frères, il me confia ses craintes : les Frères nous utilisaient, en tant qu'officiers, pour leur propre intérêt et non pour celui de la patrie. Je lui confiai mes sentiments; et nous convînmes que nous nous étions compromis plus que nécessaire avec ce mouvement et qu'il fallait se retirer. Certes, il est impossible de dire : tel jour, nous quittâmes le mouvement. Mais les doutes emplissaient nos cœurs, nous ne nous entendions plus et nous ne manifestions plus aucun zèle ou enthousiasme ; Gamâl et moi nous éloignâmes progressivement (...) Dès le début

(de) 1947, notre relation, à Gamâl et moi, avec les Frères, était très distante. »

La relation de Muhyî al-Dîn appelle des commentaires. Tout d'abord, il n'est pas le seul à avoir été « choqué ». On sait que 'Âmir'127 fut celui qui prit le plus mal l'alliance avec Sidqî. Abû al-Fadl al-Gîzâwî mit un terme à ses contacts avec les Frères ou les quitta peu après celle-ci. Ensuite, il faut préciser qu'une lecture "en filigrane » des relations des Frères ${ }^{128}$ ayant abordé la question de leur alliance temporaire avec Sidqî permet de mieux comprendre l'attitude d'al-Bannâ. Certes, des considérations matérielles jouèrent un rôle important, voire décisif (les dénégations de shâdî ne sont pas convaincantes sur ce point : il affirme qu'il n'y avait pas accord avec Sidqî, ce dernier ne faisant que reconnaître les «droits naturels " des Frères ${ }^{129}$ ). Mais le précédent gouvernement, celui de Nuqrâshî, avait fait ouvrir le feu sur les manifestants Frères et 
cette bavure avait entraîné son renvoi, chose dont al-Bannâ ne pouvait que se féliciter. Le nouveau Premier ministre, Sidqî, et le Palais ayant fait des "avances ", pourquoi refuser, pourquoi ne pas accorder le bénéfice du doute et une seconde chance à l'homme d'État dont les principaux torts étaient d'avoir abrogé en 1931 la Constitution et d'être l'ennemi du Wafd, types de torts auxquels les Frères pouvaient être indifférents? Par ailleurs, les Frères affirment avoir su prendre à temps leurs distances avec Sidq $\hat{1}^{130}$, point qui peut être certes discuté131. Sans doute, l'attitude d'al-Bannâ est très "opportuniste ", mais, de son propre point de vue, elle n'est pas forcément la « trahison d'idéaux » que Nâsir, Muhyî al-Dîn et tant d'autres, ont décelé. Il est possible d'expliquer leur réaction par l'idéalisme de la jeunesse (ils ont moins de trente ans); mais nous préférons y voir une preuve supplémentaire du malentendu sur les priorités entre officiers et Frères. Sidqî (certes un homme d'État) était aux yeux de l'immense majorité des militants nationalistes un anglophile notoire ${ }^{132}$, partisan d'une entente avec les puissances occidentales, et un « ennemi du peuple » : aux yeux de nationalistes radicaux, « rien de bon » ne pouvait sortir de lui ${ }^{133}$. Il reste qu'al-Bannâ, en faisant ce choix, va, par opportunisme plus que par conviction, "à contre-courant» de la majorité populaire, galvanisée par la question nationale. En ce sens, il commet une très grosse erreur - mais non, stricto sensu, une trahison de ses idéaux. Très grosse erreur, parce que son choix peut accréditer, temporairement peut-être, mais en tout cas assez inutilement, soit la thèse de Muhyî al-Dîn - les Frères sont un groupe politique aussi opportuniste et hypocrite que les autres -, soit celle d'un mouvement qui ne s'intéresse pas vraiment aux revendications nationales - celle du militant Husayn Tawfîq ${ }^{134}$ (soit les deux). Bien sûr, il est possible que nous sous-estimions, cinquante ans plus tard, le caractère pressant des difficultés financières de l'époque et de leur impact sur la vision du Guide suprême.

En conclusion, notons la similitude des accusations réciproques entre futurs officiers libres et Frères : l'incapacité, ou le refus, d'admettre une pluralité d'échelles de valeurs ou de conceptions de la norme éthico-ontologique, et/ou les conséquences logiques de cette pluralité, a pour corollaire l'accusation du déviant (l'Autre) de soif du pouvoir, d'attachement égoïste à des intérêts privés, etc. La norme ne pouvant qu'être Une, celui qui n'y adhère pas n'en a pas, n'en respecte aucune et est égoïste, etc. Certes, cette incapacité est fortement tempérée par une valorisation de "l'être-ensemble", privilégiant la recherche de l'unité (et du compromis), et aussi par le respect ou l'amitié que l'on peut éprouver pour un membre de l'autre camp; mais les exceptions sont toutes individuelles. L'existence, dans un camp, de "Justes", ne rachète pas ce camp. Précisons enfin qu'il n'est pas dans nos intentions de renvoyer dos à dos les deux parties. À nos yeux, dans cet épisode (et dans d'autres), les officiers nationalistes ont raison contre al-Bannâ.

En 1947-1948, les officiers entraînent les volontaires Frères. Deux incidents, rapportés par le futur Officier libre Muhsin 'Abd al-Khâliq ${ }^{135}$, ont très probablement eu, du fait de la relative renommée des deux militaires concernés, de profondes répercussions sur, d'une part, les officiers de l'artillerie (le corps du narrateur et de son compagnon), et de l'autre, sur les militaires activistes, notamment le groupe de Gamâl Mansûr (cf. infra), auquel ils appartenaient. Nous savons aussi que les deux protagonistes eurent, peu après ces incidents, de longs entretiens avec Nâsir, au cours desquels ils abordèrent plusieurs sujets, dont les libérations nationales menées à bien par Garibaldi et Ataturk (références curieuses pour un Frère, admettra-t-on) ${ }^{136}$. Il semble probable qu'ils aient 
également abordé la question des relations avec les Frères. Bref, le témoignage de 'Abd al-Khâliq est intéressant et doit être ajouté au dossier :

«(en entraînant les Frères), nous [l'auteur et le futur Officier libre Fathallâh Rifcat, qui seront tous deux décorés en 1948) découvrîmes très vite nos divergences d'opinion et d'approche (ikhtilâf fi-l-ra'y wa-l-fikr). Avec nous (au camp de volontaires d'al-cArîsh), il y avait le shaykh Hasan Sâbiq [erreur curieuse : il s'agit du shaykh Sayyid Sâbiq] et Muhammad Farîd 'Abd al-Khâliq (...). En vérité nous étions, au plus haut degré, des sympathisants des Frères, et ce jusqu'à la campagne de Palestine, où nous découvrîmes que leur pensée était très différente de la nôtre. Nous lisions le livre de Mao sur la guérilla, des ouvrages militaires, et nous entraînions les Frères. (...) (Nous venions) d'une armée régulière, avec ses règles, ses tactiques, et les Frères [comprendre : le shaykh Sayyid Sâbiq] disaient : "Il faut que vous combattiez en un seul rang, comme un mur" [il s'agit d'une interprétation «à la lettre » d'un verset coranique]. Son sens [celui du verset] n'est pas littéral. Si les Frères sont debout, en un rang, comme un mur, n'importe quel canon peut les faucher en un instant (...) Puis eut lieu l'incident célèbre, avec pour victime un enfant musulman de douze ans, dont le sang bouillait de patriotisme, et qui avait voulu prendre part aux combats. Son grand-père, qui était son tuteur, vint le reprendre, et le ramena de force à la maison, malgré la résistance de l'enfant. Ce dernier revint, quelques jours après, au camp. Le grand-père revint nous dire : je ne suis pas venu le reprendre, pour moi, il est mort. Est-il logique d'envoyer un enfant à la guerre? Un enfant peut-il guerroyer? Dès la première bataille, nous récupérâmes son cadavre. On aurait dû tenir compte (des capacités) de cet enfant, du travail qu'il pouvait accomplir, au lieu de le faire participer à une bataille sauvage contre les Juifs. Les grandes différences entre les Frères et nous surgirent. Nous demandâmes au bureau de direction des Frères de venir à al-cArîsh et alBannâ nous envoya quelques Frères (...). Mahmûd Labîb nous demanda si nous voulions organiser une prise du pouvoir et quelle était notre conception du gouvernement islamique. Nous discutâmes, mais toutes leurs réponses étaient mystérieuses. Nous décidâmes de rester amis : nous entraînions les Frères, mais, intellectuellement, nous nous séparâmes d'eux. »

Retenons d'abord de ce texte que les incidents sont perçus comme révélateurs de mentalités « Frères » et «militaires nationalistes » différentes, séparées par un fossé, qui n'était pas immédiatement reconnu. Signalons que 'Abd al-Khâliq qualifie l'épisode de l'enfant comme étant « célèbre » (hâditha shahîra), ce qui veut dire qu'au moins celuici eut un grand retentissement dans l'armée. Étudions ensuite l'incident de l'enfant, qui est le plus facile à interpréter : même si elle n'occupe pas tout à fait la même place dans leur Weltanschauung, les militaires nationalistes ne contestent pas la validité de la lecture islamiste de l'obligation du jihâd, et, comme eux, la perçoivent comme impliquant la prise des armes contre l'ennemi (même si pour eux l'ennemi est au moins autant celui de la patrie que celui de la religion, avec confusion possible des deux registres). Mais le jihâd n'implique pas irrationalité ou inhumanité ou encore déchaînement aveugle des passions. Un enfant de douze ans doit rester en famille ou participer à la guerre autrement qu'en prenant part aux combats. Le jihâd ne justifie pas le bouleversement de l'autorité familiale si celui-ci n'est pas nécessaire. Il ne signifie pas efforts non planifiés ou inutiles. Le sacrifice et l'héroïsme doivent être "téléologiques ", ils ne sont pas une fin en $\operatorname{soi}^{137}$. En résumé (et c'est un reproche fréquemment fait aux islamistes par le savoir conventionnel des musulmans très pratiquants), les Frères sont accusés de déchaîner des passions «fanatiques » qui, outre qu'elles deviennent incontrôlables, empêchent toute réflexion et organisation sereines, nécessaires pour accomplir les obligations définies par le sacré, c'est-à-dire par le patriotisme et/ou la religion. Il semble probable que les acteurs aient pris confusément 
conscience du fait qu'il y a là plus qu'un simple trait psychologique collectif. En effet, ils parlent de différence de mentalité (caqliyya). À nos yeux, ce trait, dénoncé, semble devoir être mis en relation avec, ou expliqué par, une tendance structurelle, certes probablement surmontable, résultant des effets pervers de ce que Shayegan et Roy ${ }^{138}$ appellent l'idéologisation de la tradition (ou de l'islam), conjuguée à la structure d'un groupe constitué par l'adhésion à une idéologie ${ }^{139}$, et à ce qu'il faut bien appeler une méfiance radicale vis-à-vis de l'environnement en général et du "politique » en particulier, illustrée par la popularité des théories du complot: dans ce contexte, les solutions modérées (qui, précisons-le, ne sont pas toujours les meilleures) sont toujours suspectes, en ce qu'elles apparaissent comme autant de concessions à l'environnement, à l'époque, etc. La sincérité de l'engagement n'est prouvée que par le refus (quelquefois stupide) des compromis(sions). Quoi qu'il en soit, l'épisode (comme l'autre, d'ailleurs) rend urgent de savoir si les Frères savent ce qu'ils veulent faire dans le cas d'une prise du pouvoir (hypothèse d'actualité en 1948). L'on pose la question ${ }^{140}$. Et la réponse sera jugée, à tort ou à raison, négative ou au moins insatisfaisante.

L'interprétation de l'épisode du shaykh Sayyid Sâbiq est plus délicate. Il est difficile de déterminer si la réaction des officiers fut surtout instinctive ou si elle s'accompagnait de la formulation, même in petto, de reproches précis. Et si c'est le cas, quels étaient ces reproches? cAbd al-Khâliq ne les précise pas, ce qui veut dire qu'ils lui semblent évidents. Cette supposition "d'évidence » nous permet de tenter de formuler des hypothèses, sans support documentaire explicite. Il peut s'agir, d'abord, d'une critique d'une interprétation du Coran, éventuellement qualifiée d'arriérée (mutakhallifa) ou de «bornée/crispée/fanatique » (mutazamitta, mutacassiba, qui sont les termes qu'utilisera Nâsir pour désigner les Frères). Ce n'est pas un attachement à la lettre plutôt qu'à l'esprit du Texte qui est diagnostiqué et critiqué (supposer que la lettre peut trahir l'esprit dans un texte émanant de Dieu est une idée qui ne peut être envisagée par un croyant, nous semble-t-il). Mais plutôt un refus ou une incapacité, pour comprendre le Texte sacré, pour distinguer préceptes, injonctions et métaphores, d'avoir recours à ou de tenir compte des acquis de la science, de la technique ou du savoir-faire. Un expert stratégique, un homme ayant une expérience minimale de la guerre, un homme doté d'un simple bon sens, doivent voir que cette injonction coranique est métaphorique et appelle à l'union et à la solidarité des guerriers musulmans, sans préconiser telle ou telle tactique. D'un seul incident est diagnostiquée une incapacité des Frères (et non, insistons, de leur credo) à faire face au monde moderne. Être musulman n'inclut pas d'avoir une lecture auto-centrée sur les textes sacrés et leurs commentaires. Il faut, conformément à l'injonction du Prophète, "chercher la science même en Chine", même, donc, dans les ouvrages de Mao. Pour être juste, il faut ajouter qu'al-Bannâ et une majorité de Frères auraient certainement approuvé la critique - quitte, pour certains, à ne pas forcément en tirer toutes les conséquences. Il peut également s'agir d'un refus de la domination «d'entrepreneurs religieux " (culamâ' ou entrepreneurs indépendants) sur l'ensemble des sphères de la vie sociale. Le primat du religieux n'implique pas celui des "religieux », n'entraîne pas un non-respect de la division du travail et ne doit pas remettre en cause l'autonomie de certaines branches, et notamment celle de la science. La religion est mieux servie par des militaires sachant faire leur métier que par des ulémas se mêlant de stratégie ou de tactique. Les militaires nationalistes déduiront-ils de ces deux critiques - auxquels tous, cAbd alRa'ûf et Hammûda compris, adhèreraient - un refus «conscient de soi » du primat du 
religieux ou au moins une autre définition de ce primat, ou encore une conception " autre» des rapports entre politique, patrie, et religion? Il semble difficile de répondre à cette question. Les réponses sont probablement aussi nombreuses que le nombre d'individus concernés, avec une majorité gravitant à l'époque autour d'une formulation du type : «il est très important d'être religieux, de respecter la religion, mais il est aussi très important d'être tolérant, de "faire avec" dans ce domaine, et la priorité absolue doit aller à la libération nationale, et non à la formation d'un homme nouveau ».

Dès 1947, mais surtout en 1948-1949, les villes égyptiennes sont marquées par un déferlement de violence politique ${ }^{141}$. Il s'agit d'opérations contre les troupes britanniques, certes. Mais il existe aussi une agitation ouvrière et estudiantine souvent réprimée dans le sang, un saccage de plus en plus fréquent des magasins durant les manifestations, et une vague d'attentats, de plus en plus aveugles, contre les cinémas, les centres de police, le quartier et les intérêts juifs, etc. Les responsabilités sont certes partagées entre les diverses parties, à l'exception relative du Wafd, mais celles des Frères, quoi qu'aient pu dire leurs hagiographes, sont écrasantes ${ }^{142}{ }^{143}$. Le fait qu'alBannâ se soit fait piéger par son collaborateur al-Sinâdî nous semble une explication beaucoup trop commode - ce qui ne veut pas dire toujours entièrement erronée. D'autre part, commenter la violence en affirmant, plus ou moins explicitement, qu'il s'agissait d'actes patriotiques courageux ne visant que des juifs, comme l'a écrit Sâlih Abû Riqî $q^{144}$, est à la fois moralement odieux - les juifs faisaient d'ailleurs partie du peuple égyptien - et factuellement faux. L'effet sur les officiers est désastreux. Précisons que ce n'est pas forcément le principe (défendu et préconisé, rappelle-t-on, par 'Azîz al-Masrî) de l'attentat contre un «traître » qui les choque tous à l'époque ${ }^{145}$ même si un futur Officier libre, Ahmad Tucayma, quitte les Frères musulmans parce qu'il « veut libérer son pays et non devenir un assassin, le meurtre étant un des péchés les plus graves (...). Je ne suis pas Dieu pour décider de qui est traître et qui ne l'est pas. $»^{146}$ C'est le caractère de plus en plus aveugle de ces attentats, leur inutilité, le désordre qu'ils introduisent, alors que le pays est occupé et/ou en guerre, leur rôle dans la disparition de la concorde entre nationalistes égyptiens, alors que la cause nationale ne progresse pas. Citons cukâsha: "La compromission des Frères dans des choses mystérieuses, comme les assassinats et autres actions apparentées, nous inspira de la répulsion et nous fit prendre conscience de la nécessité de créer une organisation globale n'adhérant à aucune doctrine sectaire. $»^{147}$ La fiction d'un peuple uni dans ses efforts contre l'envahisseur est malmenée par les faits et surtout par les Frères, qui tuent d'autres Égyptiens. Assassiner (entre autres) le juge al-Khâzindâr parce qu'il a condamné des Frères à des peines de prison pour voies de fait et parce qu'il a déclaré, au cours du procès, que la présence britannique se fondait sur un traité signé par un gouvernement représentant la nation, donc légal et légitime, tuer des policiers, que ce soient de pauvres "shâwîsh" ou le Hâkimdâr (préfet de police) Salîm Zakî, par mégarde ou non ${ }^{148}$, fomenter des attentats contre les quartiers et les institutions « juifs » ${ }^{149}$, sans prendre garde au nombre de civils tués, organiser des raids contre le siège du parti d'Ahmad Husayn ${ }^{150}$, tuer un des militants de ce parti ${ }^{151}$, autant d'actes qui leur aliènent une bonne partie, voire la totalité de la classe moyenne ${ }^{152}$. Plusieurs Officiers, dont Nâsir, en tireront les conclusions qui à leurs yeux s'imposent. Une d'entre elles est que les Frères sont une faction politique - aucun des deux termes n'est élogieux - dont les exigences en matière de morale, en ce qu'elles se traduisent au moins par un jugement sur les «déviants ", sont un facteur de division et de violence, 
ayant des conséquences négatives sur l'action. "Doctrine sectaire" (muctaqad madhhabî), groupe politique (jamấa siyâsiyya), groupe fanatico-borné (jamâca mutazamitta, mutacassiba), voilà les termes utilisés par cUkâsha, Khâlid Muhyî al-Dîn et Nâsir, trois anciens membres de la confrérie ${ }^{153}$. Dans le même ordre d'idées, relevons aussi la très intéressante formulation de Husayn al-Shâf ${ }^{\complement} \hat{1}^{154}$, membre du CCR, officier réputé très dévot et pourtant très hostile aux Frères : «Il est nécessaire de distinguer l'islam en tant qu'islam et les Frères en tant qu'organisation (...) [Ce rappel est significatif. Sa nécessité sous-tend que la chose ne va pas, et n'allait pas de soi]. Les Frères étaient la première organisation [politique] à proclamer son identité islamique dans son propre nom (...) Pour ce, il était difficile de s'opposer à eux, jusqu'à qu'à preuve du contraire [contraire du caractère islamique] dans la pratique (...). Le terme Frères musulmans outrepasse l'appellation que Dieu a réservée aux musulmans. N’a-t-il pas dit : "Il vous a nommés musulmans" (...) [Il cite ensuite d'autres versets coraniques]. Allâh n'a pas dit "Frères musulmans", ils ont inventé un statut non mentionné par le Coran, sauf en tant qu'invitation à l'union et à éviter la dispersion [Référence au sens $\mathrm{du}$ verset : les musulmans sont frères]. Leur nom, au contraire, invite à la division et au dispersement (...) Les Frères s'imaginaient avoir trouvé une nouvelle fondation (asâs jadîd) pour l'islam, alors que celui-ci a été fondé par le Maître de l'Univers (...). Ils pensaient être les envoyés de la Providence divine, qu'ils pouvaient donner à untel le label "musulman" et à tel autre "non musulman". » Ce n'est pas une simple querelle sur les termes. La critique de Shâfî,, outre le fait qu'elle se place d'emblée sur le terrain favori des Frères, celui de l'interprétation du texte sacré, ne critique pas des «pratiques» qui pourraient être présentées comme autant d'accidents malheureux, mais des choix fondamentaux. Ajouter le terme « Frères » à "musulmans ", c'est d'une part, faire le choix de la division, en créant un sous-groupe dans le groupe, une souscommunauté dans la communauté, de surcroît se chargeant de juger de la foi des uns et des autres, et, d'autre part, détourner le sens du texte sacré, en transformant un appel à l'union en légitimation de division. Il convient néanmoins de préciser que la lecture de l'ensemble du texte de Shâfî ne permet pas de déterminer si ce dernier souligne un risque découlant d'une option ou s'il diagnostique une conséquence inéluctable de celle-ci. En effet, il précise que les Frères n'ont pas toujours été ainsi et reproche plus loin aux groupes islamistes contemporains d'insister sur les "points de discorde" plutôt que sur les "points communs". D'autre part, sa critique, qui affirme brutalement aux Frères qu'ils ne sont pas l'umma (ou l'islam), peut-être interprétée comme un rappel de la nécessité, pour qui veut représenter celle-ci, de prouver, par des actes, qu'il en est capable ou digne, etc. Quoi qu'il en soit, Shâfî a le mérite de réfuter, en recourant aux catégories du sacré, l'explication par l'accident malheureux ou par le mauvais choix individuel. Ce sont des logiques discursives essentielles qui sont mises en cause et dont les dangers sont soulignés. Nous ne savons pas non plus si ces réflexions sont celles qu'il fit à l'époque ou constituent ses conclusions de 1993. Mais, même s'il les avait formulées autrement à l'époque, lui et Kamâl Husayn, pourtant proches par leurs conceptions des islamistes, choisirent Nâsir - contre les Frères.

Notons, dans le témoignage précité de "Ukâsha, l'emploi du terme "mystérieux" (ghâmid), qu'utilisent également Muhsin 'Abd al-Khâliq, pour qualifier les "réponses " de Labîb ${ }^{155}$, et le penseur réformiste Khâlid Muhammad Khâlid, pour décrire son malaise ${ }^{156}$. Abû al-Fadl al-Gîzâwîn ${ }^{157}$, autre Officier libre qui fit un (bref) séjour chez les Frères, parle "d'obscurité" (mubhama). Sâdât affirme avoir éprouvé une "crainte 
obscure », et parle de " mystère ». Il explique qu'al-Bannâ, personnage « énigmatique ", " disait une chose et cachait en lui plusieurs autres " ${ }^{158}$. Nâsir se plaint fréquemment de ne pas « comprendre » ce que veulent les Frères ${ }^{159}$. Les demandes de Khâlid Muhyî alDîn, relatives au programme des Frères, traduisent la même perplexité vis-à-vis d'un manque de transparence et portent toutes sur les questions du programme et de l'autorité. Les Frères, à l'instar de Mahmûd Labîb, aimaient déclarer : « Nous avons le Coran et la Sunna, tout le reste est détails $»^{160}$, en expliquant aux Officiers qu'un programme serait source de divisions. Le rejet de ce type d'explications par les officiers ne traduit pas seulement une irritation face au caractère «vague » de cette attitude; après tout, le programme des Officiers libres ne brillera pas par son élaboration : eux aussi éviteront les «détails superflus " par crainte des querelles. Là n'est pas le problème central. Celui-ci réside dans ce qui est perçu par les officiers comme une instrumentalisation du sacré à des fins politiques, une sacralisation, si l'on veut, d'une autorité - et qui est probablement une incapacité à ou un refus de penser le politique et le problème de l'autorité, tous deux occultés par le charisme d'al-Bannâ, aspect par lequel les Frères sont effectivement un mahdisme ${ }^{161}$. Citons Muhyî al-Dîn ${ }^{162}$, qui pose relativement bien le problème: "Se fonda en moi, à l'époque, une conviction essentielle : les groupes politico-religieux ne veulent pas élaborer de programmes; car si un programme existe, s'achève le rôle du Guide ou du Prince. Au moment où le programme naît, il devient l'arbitre, ce qui tranche entre la direction et l'adhérent; le programme est un produit humain; le Coran est la parole de Dieu. Là je découvris le point faible principal de tout groupe politico-religieux : ils sont une force dans la vie politique, mais le danger réside en ce que tu ne peux pas demander des comptes quant à leur comportement politique en t'appuyant sur un programme précis. Pour cette raison précise, nous nous heurtâmes à eux. $»^{163}$ À tâtons, Muhyî al-Dîn découvre que les Frères revendiquent un statut divin à leur discours, qui rend impossible tout dialogue, toute représentation, toute évaluation. Nous avons vu que, dénonçant le caractère factice de ce procédé, il disait à Labîb et al-Bannâ : « Nous sommes tous musulmans, et après ? Être musulman ne rend pas impossible le désaccord. » Les prémisses de Muhyî al-Dîn, de Shâfî, de Nâsir, de Gîzâwî (qui parle des «intérêts privés [comprendre: sectoriels, factionnels] obscurs et flous des Frères ${ }^{164}$ ) et probablement des autres Officiers, s'énoncent ainsi : les Frères ne sont ni l'umma (égyptienne), ni ses seuls représentants, ni son meilleur porte-parole, mais une force politique. D'une part, quid du Wafd? D'autre part, et plus important, les choix politiques concrets des Frères soutenir Sidqî, pratiquer les attentats contre des Égyptiens non "traîtres" - vont à l'encontre de ce qui est supposé être la "vox populi», et ne peuvent en aucun cas s'expliquer par des « impératifs » islamiques, mais par des «intérêts privés flous », ne se reconnaissant pas ainsi.

Il apparait aux yeux des Officiers que le refus de formuler un discours autre que le Coran, qui est la foi de la majorité des Égyptiens, s'il a le mérite de «brasser large » avec une formidable efficacité, a l'énorme inconvénient de soustraire la direction Frère à la critique et de lui conférer une autorité d'autant plus démesurée : a) que ses choix politiques concrets, très partisans, dictés par les intérêts privés et/ou sectoriels, ne la justifient en rien ; b) qu'elle ne se limite pas au seul politique ou au seul espace public ; c) que l'organisation des Frères, outre son autonomie par rapport au reste de la société, ne brille pas par sa transparence; et d) que son recours à la violence est inconsidéré. Hasan al-Bannâ réclame un "chèque en blanc " : les Officiers le lui refusent. Le refus par le Guide suprême $d u$ «jeu» politique, le refus du jeu des discours et des 
programmes, humains, donc critiquables, est inadmissible ou ne peut être admissible que s'il l'on a un comportement qui incarne la norme patriotique et religieuse, ou qui peut être présenté comme une défense de celle-ci. Ce n'est pas le cas d'al-Bannâ aux yeux des Officiers: n'est défenseur du Sacré que celui qui est en permanence le défenseur de tout le sacré, patriotisme compris. Il est utile de rappeler que les critiques formulées par les Officiers émanent de personnes ayant adhéré ou ayant éprouvé de la sympathie pour les Frères. Notre propos est historique, non philosophique. Il n'a pas été question de passer en revue l'ensemble des critiques qui "pourraient» être formulées contre le mouvement ou de "tester " avec rigueur le statut, la validité, le caractère systématisable de celles qui l'ont effectivement été ou, a fortiori, leur pertinence théologique. Enfin, par plusieurs aspects, sur certains plans, le « rejet » des Frères par les Officiers était davantage un refus de leurs agissements qu'un rejet de leur discours ou de leur interprétation coranique, les premiers n'étant pas alors perçus comme une conséquence logique ou un risque potentiel, découlant du second. Nâsir, interviewé par Morgan, affirmera : « Les agissements (tasarrufât) des Frères étaient une forme de fanatisme religieux. ${ }^{165}$

La rupture entre Nâsir et les Frères

'Ukâsha et Hammûda ${ }^{166}$ sont d'accord pour affirmer que les relations entre les Frères et les cellules d'officiers dépendant d'eux sont interrompues par la guerre de Palestine. D'une part, les officiers guerroient loin du Caire ; de l'autre, le mouvement de Hasan alBannâ est dissout par le gouvernement de Nuqrâshî en décembre 1948, suite à divers attentats, dont l'assassinat d'al-Khazindâr et du Hâkimdâr Salîm Zakî, et à des explosions dans des lieux publics. Plusieurs de ses membres sont arrêtés. L'assassinat de Nuqrâshî le 28 décembre est suivi d'une aggravation de la répression, qui démantèle une partie du mouvement et désorganise l'autre. Nominalement, cependant, Nâsir et plusieurs Officiers restent affiliés aux Frères. Le premier accrochage entre cAbd al-Nâsir et 'Abd al-Ra'ûf date de septembre 49 - Mahmûd Labîb est encore " opérationnel », plus pour très longtemps. Laissons ' $\mathrm{Abd}$ al-Ra'ûf le rapporter dans ses Mémoires ${ }^{167}$ :

«En septembre 1949, Gamâl 'Abd al-Nâsir m'expliqua, lors d'une permission au Caire, qu'il voulait faire un coup d'État et qu'il ne pouvait rassembler les Officiers autour des principes du mouvement des Frères musulmans, avec leurs critères bornés et fanatiques, exigeant des officiers pressentis pour l'organisation qu'ils évitent la consommation d'alcool, les jeux de hasard et les femmes de mauvaise vie, qu'ils effectuent leurs prières, qu'ils soient aimés de leurs soldats, que leurs femmes portent l'habit islamique et qu'ils obéissent au bureau de "guidance" des Frères [la plus haute instance du mouvement]. À titre d'exemple, il me rappela que Khâlid Muhyî al-Dîn avait quitté les Frères en 1947 pour devenir marxiste et rejoindre les rangs d'Iskra. Notre discussion se prolongea, dura plusieurs heures, chacun de nous restant sur ses positions. Nâsir voulait enrôler le plus grand nombre possible d'officiers, quelle que soit leur moralité laxiste, et ne pas exiger des officiers que les femmes de leur famille portent l'habit islamique. Il s'opposa avec force au principe d'une obéissance des officiers aux décisions du bureau de guidance des Frères musulmans, qu'il taxa de "fanatisme borné" (tazammut). Je répondis en affirmant que le laxisme en matière de recrutement nous exposerait aux coups des mukhâbarât, et que le non-port de l'habit islamique par nos femmes ferait de nous la risée de nos soldats, tant lors des fêtes religieuses et patriotiques que sur la voie publique. Quant aux décisions du bureau de guidance, elles ne sont prises, dis-je, qu'après examen pointilleux par les experts du mouvement. Les événements ont prouvé la correction des décisions du bureau de guidance. Enfin, ajoutai-je, l'histoire des Frères est pure, éclatante, sur tous les plans, politique, social et militaire. Enfin, le principe de solidarité est appliqué à chaque fois qu'un Frère est 
dans le besoin ou est "coincé". Le mouvement a 400 sections en Égypte, où le Frère peut être soigné et faire du sport. La discussion prit fin et nous convînmes de nous éclairer en demandant à 'Azîz al-Masrî son opinion. Je transmis l'opinion de Nâsir à Mahmûd Labîb. Nous allâmes, Nâsir et moi, chez 'Azîz al-Masrî. Après avoir écouté nos avis respectifs, il affirma: “Euvrez ensemble pour chasser d'Égypte les Britanniques, puis poursuivez la lutte pour l'abolition de la monarchie - je vous mets en garde contre l'inimitié (entre vous), car elle dispersera vos forces. Si vous êtes incapables de collaborer ensemble, marchez vers l'objectif, en deux lignes parallèles". Je répondis : "J'agirai selon ce conseil, dans la mesure où les ordres de la direction des Frères le permettent". Nâsir déclara: "Mon premier objectif est l'abolition de la monarchie". M'ont rejoint au sein des Officiers libres des officiers qui furent assiégés avec moi à al-Fâlûdja, comme Salâh Sâlim. đuvrent avec nous 'Abd al-Hakîm 'Âmir et Khâlid Muhyî al-Dîn. J'allai ensuite rencontrer Labîb, lui rapportai ce qu'avaient déclaré Nâsir et al-Masrî, et moi-même. Il me dit : "Va dire à Gamâl que les Frères musulmans sont fanatiques et (encore) fanatiques (fanatiques et fiers de l'être)". »

47 Les récits de ${ }^{c} \mathrm{Abd}$ al-Ra'ûf ne le disent pas explicitement, mais il semble que les Frères aient, probablement après l'assassinat d'al-Bannâ, durci leurs positions en matière de recrutement. Nous l'avons vu, le «laxisme » de Nâsir en matière de respect des préceptes islamiques les irritait déjà, mais ils avaient accepté - ou fait semblant d'être convaincus par - son plaidoyer pour le gradualisme. Quoi qu'il en soit, nous savons que Nâsir prit très mal les remarques sur le principe de "solidarité ", que 'Abd al-Ra'ûf semble avoir formulées à plusieurs occasions. Le ra'îs présente ainsi l'argument de cAbd al-Ra'ûf : «Il disait que c'est un mouvement puissant et que si l'un de nous était arrêté, ce mouvement pouvait prendre en charge ses enfants et lui garantir son avenir; nous répondîmes que celui qui veut œuvrer dans le champ patriotique (yashtaghil fî-lmawdûc al-watanî) ne pense ni à ses enfants ni à son avenir (...) ${ }^{168}$ ». Nâsir ajoute que tous les Officiers partagèrent son opinion. Il est également probable qu'il prit fort mal les réflexions sur les mukhâbarât, et dut y voir une preuve de l'esprit sectaire des Frères, incapables de reconnaître des vertus à ceux qui ne faisaient pas partie de leur mouvement, prompts à attribuer les pires tares à autrui ${ }^{169}$. Le sacîdî (originaire de Haute-Égypte) qu'il était ne dut pas apprécier davantage les allusions aux femmes d'officiers. Enfin, il semble évident que la "promesse » de ${ }^{\mathrm{c} A b d}$ al-Ra'ûf à al-Masrî ne l'engage à rien, puisqu'elle est conditionnée par sa compatibilité avec les ordres émanant de la hiérarchie des Frères et que Nâsir a cherché à montrer qu'il n'était pas seul, mais qu'il avait réussi à entraîner plusieurs officiers prestigieux. 'Ukâsha a formulé différemment ${ }^{170}$ le différend entre Nâsir et ${ }^{\mathrm{c}} \mathrm{Abd}$ al-Ra'ûf :

« La compromission des Frères (...) poussa les Officiers à découvrir la nécessité pour eux d'une organisation globale, ne se liant à aucune doctrine sectaire. Une organisation comprenant en son sein tous les citoyens égyptiens, quelle que soient leur religion ou leurs convictions politiques, tant que leur objectif était (le service de) l'Égypte, la mère-patrie. Là éclata le différend entre nous autres officiers et le regretté ${ }^{\mathrm{c}} \mathrm{Abd}$ al-Muncim ${ }^{\mathrm{C}} \mathrm{Abd}$ al-Ra'ûf, qui avait succédé à Mahmûd Labîb après le décès de ce dernier : il estimait que l'organisation ne devait admettre que ceux qui avaient pour foi l'islam et qui étaient d'une foi intransigeante (tashaddud fi-al-islam). De surcroît, contrairement à notre opinion, il estimait que les cellules d'officiers devaient être totalement dépendantes du pouvoir des Frères. Ce différend fut l'incitation à la création des Officiers libres. "

Kamâl al-Dîn Husayn pose le problème d'une manière plus concrète, plus historique :

«Après, [le retour de Palestine], nous prîmes un temps de repos, pour ne pas attirer les regards. Puis nous décidâmes [sic, il eût fallu écrire : observâmes] que l'armée 
(...) n'était pas traversée par un seul courant, mais par plusieurs autres. Gamâl suggéra que l'armée se devait d'être et d'appartenir à l'armée [al-jaysh li-l-jaysh; aljaysh bit $\hat{a}^{c}$ al-jaysh, en d'autres termes: se devait d'agir indépendamment, en fonction de l'intérêt national] et n'avoir de compte à rendre à personne d'autre : être en contact avec les autres, oui, mais devenir d'abord un seul et unique courant [réunir les diverses mouvances activistes]. Une excellente idée! À ce moment, naquit le mouvement des Officiers libres, au moment où nous cessâmes tout contact avec les Frères musulmans et où nous devînmes indépendants. ${ }^{171}$

Quoi qu'il en soit, 'Abd al-Ra'ûf reviendra à la charge plusieurs fois. Ahmad cÂdil Kamâl rapporte ${ }^{172}$ qu'en 1950, Nâsir, Kamâl al-Dîn Husayn, 'Abd al-Ra'ûf et Abû al-Makârim 'Abd al-Hayy (qui devait succéder à Labîb à la tête des cellules Frères, 'Abd al-Ra'ûf n'étant pas au Caire) se rendirent chez 'Abd al-Rahmân al-Sinâdî, chef de l'organisme secret, qui purgeait sa peine de prison à l'hôpital Qasr al-cAynî173, pour exposer

« leurs grandes divergences de vue. Gamâl disait que la voie des Frères est longue et n'aboutit à rien. À quoi sert un rassemblement d'officiers pour apprendre par cœur le Coran, les hadîth, et l'étude de la sîra (vie du prophète), etc. En quoi l'admission d'un officier patriote, non musulman, peut-elle être nuisible? Doit-on le refuser et se priver de ses efforts ? 'Abd al-Muncim contredisait les thèses nassériennes : nous sommes Frères et musulmans, nous œuvrons pour cette prédication, nous avons pour objectif l'instauration de l'État islamique, nous ne devons pas perdre de vue nos objectifs ou renoncer à approfondir la connaissance de notre religion. Kamâl alDîn Husayn approuvait Nâsir, et 'Abd al-Hayy soutenait 'Abd al-Ra'ûf. Ils demandèrent de soumettre leur différend au Guide suprême [Kamâl explique ensuite que le guide, s'il a été choisi, n'a pas encore été officiellement nommé. Ce qui permet de dater l'incident, le choix du guide ayant été effectué début $1950^{174}$. Il semble que Hasan al-Hudaybî se soit trouvé devant un fait accompli : un groupe voulait être libéré de ses obligations en tant que Frères et il ne pouvait qu'accepter (...). Hudaybî affirma alors qu'il était peut-être préférable de ne pas mettre tous les œufs dans le même panier: que les Frères poursuivent leur route et Gamâl la sienne. C'est ce que voulait Gamâl ; il répondit en affirmant qu'il demeurait un ami des Frères. "

Nous avons passé en revue les témoignages les plus solides. Il convient, enfin, de mentionner l'intéressante mais fragile version d'al-Dimardâsh al-'-Uqâli1 175, Frère musulman proche de 'Abd al-Rahmân al-Sinâdî. Celle-ci n'est probablement pas un témoignage à proprement parler, car il semble très douteux que l'auteur ait vu les faits qu'il rapporte (il n'a pas 17 ans quand la guerre de 1948 éclate). Il ne précise pas ses sources, mais celles-ci sont probablement les rumeurs ou l'information (souvent de qualité douteuse) ayant circulé au sein de l'organisme secret, dans le cercle des proches d'al-Sinâdî. Pour raisons de clarté et d'exhaustivité, nous résumons toute la version d'al-cUqâlî, même si seule sa fin concerne directement notre propos. 'Uqâlî explique qu'al-Bannâ, sentant ses jours comptés, rédigea un testament dans lequel il confiait la responsabilité de diriger les Frères, au cas où il mourrait, à Sinâdî, et au cas où celui-ci « ne serait pas là ", à Gamâl cAbd al-Nâsir. Le testament recommandait également de " préparer » dans les plus brefs délais un coup d'État contre la monarchie. Cette partie du récit est la plus douteuse. Sinâdî n'est pas le seul à s'être prévalu des dernières volontés du Guide suprême ${ }^{176}$. Les "testaments" et "dernières (ou non) volontés» d'al-Bannâ, se contredisant entre eux, semblent avoir été une « ressource » utilisée lors des querelles et guerres de succession au sein du mouvement. Au mieux, ils semblent constituer une extrapolation de propos tenus par le Guide ou de mesures envisagées un moment par ce dernier. Au pis, il s'agit d'inventions pures et simples. D'autre part, sauf erreur, Ahmad 
'Adîl Kamâl, autre proche d'al-Sinâdî, et 'Abd al-Muncim 'Abd al-Ra'ûf, qui, selon alcUqâlî, eut connaissance de sa teneur, ne mentionnent jamais l'existence d'un tel testament en faveur des chefs de file de l'organisme secret. L'historien peut émettre des doutes, mais il ne peut trancher en toute certitude. Il doit se contenter d'indiquer que ce témoignage implique qu'au sein de l'organisme secret, Nâsir était une "étoile montante ", plus important que cAbd al-Ra'ûf ou cAbd al-Hayy - ce qui expliquerait, entre autres, sa convocation par le Premier ministre cAbd al-Hâdî (mais qui n'expliquerait pas pourquoi on cessa apparemment de le surveiller après cela). Selon al'Uqâli, ce testament d'al-Bannâ fut confié à Sâlih Harb, ancien ministre de la Défense de 'Alî Mâhir, compagnon et ami de 'Azîz al-Masrî et chef de l'influente association des "Jeunes musulmans ». Harb transmit le «testament » d'al-Bannâ à Nâsir, lorsque ce dernier rentra en Égypte avec les forces assiégées à al-Fâlûdja (n'eut-il pas été plus simple de le faire parvenir à al-Sinâdî?). La version d'al--Uqâli indique (et c'est là qu'elle nous intéresse) qu'à la suite de cette "transmission ", Nâsir qui, entretemps, avait découvert en Palestine l'existence, au sein de l'armée, de nombreux groupes d'activistes, eut une réunion avec 'Abd al-Muncim cAbd al-Ra'ûf et Abû al-Makârim 'Abd al-Hayy, les deux officiers Frères les plus gradés. Après leur avoir montré le testament d'al-Bannâ et sa recommandation en faveur d'un coup d'État rapide, il leur expliqua qu'une telle tâche était impossible à mener à bien sans une association avec les autres cellules et groupes activistes au sein de l'armée et une action commune. 'Abd al-Hayy estima que Nâsir avait raison, mais 'Abd al-Ra'ûf contesta les vues de ce dernier. Il affirma qu'il ne " pouvait mettre sa main dans une main impure, ne pratiquant pas les ablutions, une main de marxiste ou de personne n'appartenant pas aux Frères musulmans ». Nâsir tenta en vain de convaincre 'Abd al-Ra'ûf. À la suite de cette discussion, conclut al--Uqâlî, Nâsir entreprit en 1949 de créer le mouvement des officiers libres, coalition de plusieurs mouvements clandestins. Cette version, on le voit, permet au moins d'établir que Nâsir rentra de Palestine avec l'intention de prendre ses distances, voire de rompre avec les Frères musulmans.

51 Ces cinq témoignages, dont trois émanent de Frères, nous donnent un accès immédiat aux reproches formulés (en 1949-1950) par Nâsir à l'encontre du mouvement. Distinguons-les rapidement :

1) Nâsir estime plus opérationnel de ne pas conditionner l'accès à l'action politique à des critères d'éthique personnelle. Les qualités qu'il exigera ${ }^{177}$ sont le « courage » et la capacité à "taire les secrets» (al-shajâa $a$ wa-al-kitmân). Ceci revient à prendre conscience, confusément ou explicitement, de la pertinence politique et de l'utilité instrumentale de la distinction entre public et privé, même si on ne la formule pas clairement. Mais nous n'avons pas assez de matériaux pour savoir s'il prend conscience à ce moment de la nécessité de distinguer les deux sphères (et de fonder cette distinction) ou s'il est simplement hostile à la multiplication des conditions d'admission " inutiles » ou "irréalistes », dont le résultat est de se priver de concours utiles et de rendre impossible l'union nécessaire à l'action. Certes, moins de trois ans plus tard, il rappellera à al-Hudaybî qu'il (Hudaybî) est incapable d'imposer le port du voile à sa propre fille et qu'il est donc irréaliste de lui demander (à Nâsir) de l'imposer à toute une société ${ }^{178}$. Ce rejet du caractère nécessaire des critères d'éthique personnelle des Frères est surtout la conséquence logique de deux lectures différentes des fins de l'action politique : Nâsir veut la libération de son pays, les Frères veulent la création d'un «musulman nouveau» (les deux parties veulent une cité nouvelle, avec une 
conception différente de sa «nouveauté»). Mais, encore une fois, l'objection nassérienne à l'objectif des Frères se contente, dans sa formulation, d'être très pragmatique : sans entrer dans des controverses doctrinales ou philosophiques, Nâsir estime cet objectif irréaliste, non politique. Et cet argument suffit à le disqualifier. Un point doit être mentionné dans ce contexte : quand Nâsir fonde les Officiers libres, il n'estime pas être en mesure de fomenter un coup d'État avant $1955^{179}$. Combiné avec les réflexions sur la «lenteur» des Frères, ce fait suggère une alternative : a) soit Nâsir pense que l'objectif des Frères - prendre le pouvoir avec uniquement des officiers Frères - est absolument irréalisable sur le court et moyen terme; b) soit l'argument invoqué par lui sur la «lenteur » des Frères n'est qu'un prétexte pour le divorce, prétexte dissimulant des réserves beaucoup plus fondamentales (ayant trait aux fondations) sur les « options » des Frères, ce qui confère un poids accru aux versions de cUkâsha et de Muhyî al-Dîn.

2) Nâsir a découvert que sa logique " patriotique » et celle des Frères sont difficilement conciliables. Il souligne avec force cette différence, en posant la question de la participation au mouvement des "patriotes» non musulmans. Il est intéressant de souligner que ce cas de figure qu'il invoque pour illustrer les différences de démarches est (en 1949) purement fictif : le seul officier libre non musulman sera recruté deux ans et demi plus tard, le soir même du coup d'État ${ }^{180}$. Pour éviter toute confusion, redisons, malgré le risque de lourdeur, que Nâsir, et a fortiori Kamâl al-Dîn Husayn ont, des grandes lignes du contenu de la norme éthique et religieuse, une conception assez similaire à celle des Frères, et que, à l'opposé, les Frères veulent sûrement voir l'Égypte libérée. Mais les rapports entre norme religieuse et norme politique, la possibilité ou $a$ fortiori la nécessité de la fondation de la seconde par la seule première, les rapports entre religion et patrie peut-être, mais surtout entre morale religieuse et patriotisme peut-on être patriote ou compétent, sans être musulman pratiquant? si oui, quelles conséquences politiques doit-on en tirer? - les priorités politiques, et la manière d'articuler entre eux les différents objectifs, opposent irrémédiablement Nâsir et les Frères. Nâsir, musulman pratiquant, croit au primat du «national »- et donc du politique - sinon dans l'absolu, du moins dans le contexte de l'Égypte de 1950. Kamâl Husayn et al-Shâfî, très dévots, lui donnent raison.

Selon les indications dont nous disposons, Nâsir ne veut pas (en 1949) débattre avec les Frères de ce qui constitue la cité idéale: il veut renverser une situation devenue intolérable. Ses propres termes, d'après Hammûda ${ }^{181}$, sont «situation politique très dangereuse " (hâla siyâsiyya khatîra jiddan) et il veut des "résultats dans un avenir proche ». Il est toutefois probable que, dès cette époque, sa conception d'une "cité idéale » et du " programme » doive plus à la logique redistributive occidentale qu'à une lecture des commentaires coraniques. Non que la validité de ces derniers soit remise en cause : ils sont perçus comme posant des principes généraux devant être traduits dans les faits - par le biais de programmes les élaborant.

Nâsir, enfin, taxe les Frères de tazammut, "fanatisme ", "bigoterie ", " étroitesse de vues ». Est-ce le caractère sectaire qu'il dénonce ? L'absence de "sens du possible »? Le risque totalitaire? Le manque de souplesse politique? Un état d'esprit qui, dominé par les passions, empêche d'avoir un vision claire du bon et du meilleur, un comportement rationnel, mieux à même de servir la norme ? Nous ne savons pas vraiment. En 1962, il déclarera à Morgan qu'il " avait été confronté à des difficultés religieuses » lors de ses contacts avec les Frères parce qu'il voulait que «la tolérance religieuse soit un 
fondement de la société nouvelle qu'il souhaitait voir s'instaurer en Égypte ${ }^{182}$. Ceci est fort possible, mais peut n'est-ce qu'une rationalisation a posteriori. Contentons-nous de constater qu'il a formulé le problème autrement en 1949. Il est intéressant de noter que Kamâl al-Dîn Husayn, qui est très proche de l'idéologie islamiste, et Husayn al-Shâfî donnent raison à Nâsir contre les Frères. Le premier a, on l'a vu, expliqué son choix en affirmant que son serment d'allégeance était un serment de fidélité à l'islam et non aux « Fréristes ». Il retourne ainsi contre eux la prétention des Frères à incarner l'islam, en affirmant que son adhésion était due à un malentendu. Il a probablement estimé à l'époque que les Frères se trompaient de priorités et qu'il fallait unir les efforts des patriotes, quel que soit leur comportement privé, contre la monarchie d'une part, et contre la Grande-Bretagne, de l'autre. Ahmad 'Abd al-cAzîz, chef des commandos "Frères" en Palestine, avait dit à Husayn que le "jihâd suprême était en Égypte ». Le cas « limite » de Hammûda, qui quitte également les Frères pour les Officiers libres, est plus ambigu : s'il est convaincu par l'analyse de Nâsir sur la nécessité de recruter des "non-frères", il continue à espérer que les officiers libres œuvreront pour l'instauration d'un État islamique. Quand, rapporte-t-il, il formule devant Nâsir le souhait de voir ce dernier s'engager à appliquer, une fois au pouvoir, les principes de la sharîa, ce dernier répond évasivement en promettant de "gouverner selon (les principes) du Coran $»^{183}$. Réponse diplomatique, réponse tactique, et qui est loin d'être un « oui ». La nuance est de taille: c'est se réserver le droit d'une ré-interprétation différente de celle des jurisconsultes "classiques", et celui de bénéficier des apports techniques, intellectuels et conceptuels "exogènes", non prévus par la sharîa, qui permettent l'instauration de la justice et la réforme de la société.

Il convient, enfin, de signaler qu'aucune des sources utilisées, Frère ou militaire, n'a mentionné la mort d'al-Bannâ et la désorganisation (en 1949-50) des Frères, comme une cause ou un prétexte de la rupture entre Nâsir et les Frères. Il est probable que ces deux facteurs la facilitèrent, mais ils ne l'expliquent pas. Quoi qu'il en soit, les Frères - ou 'Abd al-Ra'ûf et 'Abd al-Hayy si l'on préfère - découvrent très vite avoir perdu la partie. Nâsir est suivi par la plupart des cellules. Salâh Shâdî, qui avait mentionné la confidence de Lâbib sur l'abandon des critères traditionnels d'admission au sein des Frères dans le cas des militaires, explique dans ses Mémoires cette défection massive par le fait que Nâsir avait profité de la souplesse Frère pour faire enrôler des officiers qui lui devaient allégeance à lui, plutôt qu'à "l'idée islamique ", qu'ils n'avaient pas comprise : «Je ne vis pas [en 1946] la différence entre celui qui adhérait au mouvement ainsi [sans respect des critères habituels] et celui qui adhérait au mouvement, en étant auto-limité par sa fidélité (walâ') à l'islam et par son allégeance. Le premier, si sa compréhension de l'islam et des devoirs impliqués par son allégeance ne s'améliorait pas, n'était fidèle qu'à celui qui l'avait enrôlé. Le second demeurait fidèle à l'islam, même en cas d'apostasie de son chef. $»^{184}$ Notons surtout que shâdî admet implicitement que les officiers ayant adhéré aux Frères l'ont fait, non par profonde ferveur idéologique, mais parce qu'ils étaient impressionnés par la stature de Gamâl 'Abd al-Nâsir, que leur allégeance était une allégeance à ce dernier. Nous avons là la première «trace » historique concrète du charisme et de stature du futur raîs. Dans l'interview qu'il a accordée à Kirk Beattie ${ }^{185}$, l'officier libre Ahmad Tu'ayma estime que les officiers Frères, qui étaient selon lui une centaine en 1949, ne sont plus que vingt le 23 juillet 1952. Si les chiffres de Tucayma doivent peut-être être revus à la baisse, la courbe qu'ils indiquent est significative ${ }^{186}$. L'explication de Shâdî est toutefois partielle. 
Nous avons vu que la plupart des officiers ayant collaboré ou adhéré au mouvement des Frères avaient des critiques à formuler à l'égard de cette formation et que la majorité appartenait à un courant politique - la constellation Parti national/Jeune Égypte différent, en ce qu'il privilégie, comme priorité, le rapport à, et l'agir pour la patrie, tout en étant attaché à l'islam et à sa "gloire ». Le divorce n'est pas le fruit d'un seul esprit maléfique, mais celui de trajectoires multiples d'officiers musulmans, rassemblés autour de préoccupations nationalistes, estimant tous que la question nationale était plus importante que les clivages traditionnels (Wafd/Palais) ou modernes (droite/ gauche), et se refusant, après un voyage initiatique au sein ou en compagnie des Frères, à considérer ces derniers autrement que comme une faction supplémentaire, dont les pratiques n'étaient pas à la hauteur des slogans. Reste que Nasser, officier auréolé du prestige de professeur et de combattant, reconnu par ses pairs comme un homme d'une grande culture, comme soucieux de penser et d'agir par rapport aux valeurs centrales, dut être un catalyseur, en ce qu'il réussit à offrir un «choix» possible et crédible. D'autres facteurs, plus secondaires, joueront également: l'activité des Frères est désorganisée par l'assassinat d'al-Bannâ et l'agonie de Labîb. 'Abd al-Ra'ûf, contrairement à Nâsir, est étroitement surveillé par la police politique et, de surcroît, est affecté à une unité servant dans le Sinaï ${ }^{187}$. Indiquons dans ce contexte que Hammûda affirme que Nâsir réussit à convaincre Labîb, très peu avant la mort de ce dernier, de lui remettre la liste des officiers affiliés aux cellules Frères, obtenant ainsi un avantage incontestable en matière d'information ${ }^{188}$. L'anecdote nous semble peu plausible, étant donné la détérioration déjà survenue des relations entre les Frères et Nâsir, mais nous ne pouvons certifier son inauthenticité (Hammûda se trompe peutêtre seulement de date, encore que cela semble étonnant, la mort de Labîb étant un point de repère important $)^{189}$.

Commence alors une «drôle de relation » entre Officiers libres et Frères, mélange de collaborations épisodiques et de heurts occasionnels, les deux mouvements s'épiant et se concurrençant. Les Frères, semble-t-il, ne désespèrent pas de "récupérer » les récalcitrants. (cf. infra). Les Officiers libres, qui veulent être une organisation suprapartisane, comptent en leur sein des officiers idéologiquement proches des Frères, mais qui n'ont en général plus de contact avec le mouvement d'al-Bannâ et qui admettent la logique de «coalition » de Nâsir. Significativement, le mouvement n'exclura 'Abd alRa'ûf (qui proclame son allégeance organisationnelle aux Frères) qu'au début 1952, après avoir refusé (à l'unanimité du comité directeur) à plusieurs reprises ses propositions de «fusion » avec les Frères. À nouveau, la collaboration ne veut pas dire que l'antagonisme potentiel entre les deux mouvements est « oublié ». Nâsir l'a, sinon constamment, du moins souvent à l'esprit. De ce qui précède, il apparaît que l'affirmation d'olivier Carré : «On peut donc considérer que les Officiers libres furent un groupe militaire extrémiste, scissionniste, des Frères musulmans, dont le chef, Nâsir, eut l'art et la manière d'utiliser jusqu'au bout l'association mère pour la liquider une fois sûr de son pouvoir personnel absolu acquis grâce à elle ${ }^{190}$ est très inexacte. Groupe extrémiste? Groupe nationaliste extrémiste, peut-être, encore qu'il faille relativiser le propos, toute la rue égyptienne et la plupart des partis l'étant autant ou plus. Mais groupe certainement "modéré » sur le plan religieux et se définissant explicitement ainsi, vis-à-vis des (contre les) Frères, selon leurs propres comptes rendus, qui taxent les officiers de laxisme et les accusent de recruter des buveurs d'alcool et des fumeurs de haschisch. Scissionniste? Les officiers firent scission pour fonder un groupe indépendant, nouveau, différent du précédent, en ce qu'il était 
explicitement "supra-partisan", et qu'il réussit à élargir considérablement son recrutement. De 50 à 60 officiers Frères (100 dans le meilleur des cas, à nos yeux assez improbable), l'on passera à 350 en 1952. L'association mère? Oui et non, encore une fois. Certes, de nombreux Officiers libres sont d'anciens Frères, jamais très convaincus $\mathrm{du}$ reste. Ils quittent volontairement, pour des désaccords profonds, le mouvement, au plus tard en 1949. Le mouvement de Nâsir est un "enfant", pour conserver la métaphore de Carré, conçu malgré la mère, très différent d'elle, se voulant ainsi, se développant (recrutant) selon des modalités et des logiques refusées par elle. « Pouvoir personnel acquis grâce à elle »? C'est faux. Contentons-nous de rappeler les discussions entre Nâsir et les Frères, rapportées par les Frères, dont il ressort que ces derniers n'étaient pas en mesure de prendre le pouvoir par un coup d'État militaire, le recrutement «Frère » stagnant. Enfin, les Frères, eux aussi, cherchaient, en 1954, à "liquider » le coup des officiers - Nâsir gagna une course de vitesse, utilisant ruse, tromperie et violence physique inouïe - mais le mouvement des Frères n'était pas « pacifique » ou « légaliste ». Le premier coup de feu fut tiré par lui ${ }^{191}$.

\section{NOTES}

1.Gershoni Israël et Jankowski James P., 1995, Redefining the Egyptian Nation: 1936-1945, Londres, Cambridge University Press, $280 \mathrm{p}$.

2.Jankowski, James P., 1975, Egypt's Young Rebels: « Young Egypt », 1933-1952, Hoover Institution Press, Stanford University, Californie, 176 p. Cf. également le chapitre consacré aux " groupes idéologiques » in Salîm Latîfa, 1996, Fârûq wa-nihâyat almalakiyya fî Misr, Le Caire, Madbûlî, p. 655 et suivantes.

3.Sur la notion de "pacte politique », $c f$. Leca Jean, 1994, « La démocratisation dans le monde arabe : incertitude, vulnérabilité et légitimité ", in Salâmé Ghassân, Démocraties sans démocrates: Politiques d'ouverture dans le monde arabe et islamique, Paris, Fayard, 452 p.

4.Mitchell Richard, 1969, The Society of Muslim Brothers, Oxford University Press, Londres, 349 p. Ramadân, 'Abd al-cAzîm, 1982, Al-ikhwân al-muslimûn wa-l-tanzîm al-sirrî, Le Caire, Rose al-yûsuf, 510 p. Muhammad Muhsin, 1987, Man qatala Hasan al-Bannâ, Le Caire, Dâr al-shurûq, 615 p.

5.Pour des éléments biographiques sur Labîb, cf. Hammûda Husayn, 1985, Asrâr harakat al-dhubbât al-ahrâr wa-l-ikhwân al-muslimûn, Le Caire, Al-zahrâ' li-l-ilâm al-carabî, p. 28 et suivantes. Mais également ‘Abd al-Ra'ûf ‘Abd al-Muncim, 1988, Arghamtu Fârûq calâ altanâzul can al-carsh : mudhakkirât ‘Abd al-Muncim 'Abd al-Ra'ûf, Le Caire, Al-Zahrâ' li-l-iclâm al-carabî, p. 41-42.

6.Muhyî al-Dîn Khâlid, 1992, Wa-l-ân atakallam, Le Caire, Al-ahrâm. En fait, il parle de drôle de "relation », mais cela signifie " allégeance », comme le démontre la suite du chapitre.

7.Car qui ne l'est pas, au sein de l'armée ? Et d'autre part, que nous apprend cette origine? 
8.Par « modernisme radical », nous désignons les courants de pensée qui estiment que le salut de l'islam passe par un aggiornamento radical du corpus de la doctrine (par exemple du sens du terme jihâd, ou de la sanction de l'apostasie, ou du caractère licite $\mathrm{du}$ sufûr, c'est-à-dire du refus du voile, etc.) et par une définition explicitement - le terme est important - « laïque » des rapports entre religion et politique. Pour un diagnostic similaire, $c f$. Carré Olivier, Michaud Gérard, 1983, Les Frères musulmans (1928-1982), Paris, Gallimard Julliard, collection « Archives », 236 pages, p. 36. Ou Carré Olivier, 1991, L'utopie islamique dans l'Orient arabe, Paris, Presses de la FNSP, 275 pages, p. 167-168. Par contre, il faut éviter de qualifier l'Islam des Frères musulmans comme étant « l'islam populaire » - Olivier Carré évite de le faire, mais sa formulation peut prêter à confusion. Dans ce que nous appellerions « l'islam populaire », le soufisme et le culte des saints jouent un rôle que les Frères musulmans déplorent.

9.Makarius Raoul, 1960, La jeunesse intellectuelle d'Égypte au lendemain de la Deuxième Guerre mondiale, Paris, Mouton.

10.Shâdî Salâh, 1987, Safahât min al-târîkh : hasâd al-umr, Le Caire, Al-zahrâ' li-l-iclâm alcarabi, 3e édition, 442 p., p. 69, puis p. 160-162. Salâh Shâdî, Frère musulman, ne parle pas d'infiltration, mais de prédication. Tous les observateurs et acteurs ne faisant pas partie du mouvement pensent qu'al-Bannâ, dès le début des années 1940, envisageait la prise du pouvoir et s'y préparait sérieusement.

11.Shâdî Salâh, op. cit., p. 161.

12.'Abd al-Ra'ûf, cAbd al-Muncim, op. cit., p. 37.

13.Cf. Bughdâdî, op. cit., p. 13-14.

14.Hammûda Husayn, op. cit., p. 26-27

15.'Abd al-Ra'ûf, op. cit., p. 37 et suivantes.

16.Kamâl Ahmad cÂdil, 1987, Al-niqat fawqa al-hurûf: al-ikhwân al-muslimûn wa-l-nizâm alkhâss, Le Caire, al-Zahrâ' li-l-ilâm al-carabî, 358 pages, p. 33 et suivantes.

17.'Abd al-Ra'ûf, op. cit., p. 38.

18.Ibid., p. 41.

19.Il pilotait l'avion de cAzîz al-Masrî lors de la tentative d'évasion de ce dernier (mai 1941), qui se proposait de rejoindre Rashîd cAlî al-Gilânî en Irak. On sait que l'avion, dont les réservoirs d'essence étaient endommagés (ou mal fermés), n’alla pas très loin et dut se poser en catastrophe à Banha.

20.Il explique dans ses Mémoires qu'il aura été plus heureux en tant que fantassin qu'en tant qu'aviateur. Il avance les raisons suivantes : un officier d'infanterie doit maitriser les caractéristiques de toutes les armes et forces (terrestres, aériennes, navales) pour coordonner son action avec celles-ci. Il doit être fort physiquement et calme. Il doit réfléchir rapidement. L'infanterie est l'arme qui remporte, en dernière analyse, la victoire. Cf. cAbd al-Ra'ûf, op. cit., p. 39-40.

21.C'est le reproche, justifié, que fait Salâh Shâdî à plusieurs officiers et notamment Sâdât. Il cite ce dernier. Cf. Shâdî Salâh, op. cit., p. 174 et suivantes.

22.Abd al-Ra'ûf, op. cit., p. 127.

23.'Abd al-Ra'ûf, op. cit., p. 34.

24.'Abd al-Ra'ûf, op. cit., p. 291. Rashâd Mahannâ cotise également.

25.Dans tous les témoignages recueillis, ces familles connaissent, à un moment ou un autre, une gêne financière.

26.Sabrî Mûsa, 1985, Al-Sâdât, al-haqîqa wa-al-ustûra, al-maktab al-masrî al-hadîth, Le Caire, 909 pages, p. 351. 
27.C'est très explicite chez Sâdât, un peu moins chez Bughdâdî et Abâza. Cf. Al-Sâdât Anwar, 1979, Al-Bahth can al-dhât, op. cit., p. 32 et suivantes. Cf. al-Bughdâdî op. cit., p. 14 ; Fawzî Mahmûd, 1994, Wagîh Abâza yatadhakkar, op. cit., p. 82 et suivantes.

28.'Abd al-Ra'ûf, op. cit., p. 43 ; Hammûda Husayn, op. cit., p. 19.

29.Hammûda Husayn, op. cit., p. 25 et suivantes.

30.Étude reproduite in Sîd Ahmad Rifaat, 1993, Thawrat al-ginirâl Gamâl cAbd al-Nâsir, Le Caire, Dâr al-Hudâ, p. 82.

31.Il faut ajouter que, sur ce point, son livre comporte d'autres passages où il affirme que les Frères, dès qu'ils s'estimeront majoritaires en Égypte, se contenteront d'imposer au prince l'application de la sharîa, sans prendre forcément le pouvoir. Hammûda, Husayn, op. cit., p. 149. Il y a une nuance - être le censeur du prince n'est pas être celui-ci -, mais est-elle importante?

32.Ibid., p. 32. Hammûda indique que Salâh Khalîfa était déjà en contact avec al-Bannâ, sans préciser s'il avait ou non adhéré au mouvement avant eux. Khalîfa aura, dans les régimes issus de la révolution, une carrière de militaire, puis de haut fonctionnaire dans les organismes de contrôle de l'administration.

33.'Abd al-Ra'ûf, op. cit., p. 43.

34.Hammûda, op. cit., p. 32.

35.Interview par Morgan, in Sunday Times, de juin 1962, cité in Imâm, cAbd Allâh, 1971, Al-nâsiriyya dirâsa fî fikr Gamâl cAbd al-Nâsir, Le Caire, Dâr al-Shabb, 544 pages, p. 33-34.

36.Nâsir ne s'en est pas tout de suite tenu à cette version officielle. Dans ses Mémoires publiées in al-Musawwar, le 30-10-52, il a indiqué avoir rejoint « une organisation dirigée par l'officier M. L ». M. L. est Mahmûd Labîb. Il s'est néanmoins abstenu de préciser que M. L. était Frère musulman. Se recueillant (en 1954) devant le tombeau de Hasan alBannâ, il déclara aux Frères : « Ne croyez pas que je suis pour vous un étranger, ô Frères musulmans. Je suis un des vôtres. » Cité in Muhammad, Muhsin, op. cit., p. 347. Menace ou Credo?

37.Discours de Nâsir du 18-11-1965, cité in Imâm, cAbd Allâh, cAbd al-Nâsir wa-l-ikhwân, op. cit., p. 44-45.

38.C'est la version « officieuse » des Frères. Cf. Al-Hâkim Sulaymân, op. cit., p. 8-9, ou Himayd Usâma, 1986, Le Caire, cité in extenso par Sîd Ahmad Rifat, op. cit., p. 81 et suivantes. Voir aussi Shâdî, op. cit., p. 163-164. Shâdî distingue trois étapes dans l'évolution de la relation entre Nâsir et les Frères. Il ne date qu'approximativement la première (selon lui, relation avec al-Sinâdî) : elle débute après le retour de Nâsir du Soudan. Mais ailleurs, il avance la date de 1943, date, selon lui, du début des activités de 'Abd al-Ra'ûf. Or celles-ci, malgré une confusion due aux témoignages contradictoires de 'Abd al-Ra'ûf lui-même, débutent, selon toutes probabilités, en 1942. La seconde étape (relation avec Labîb, qui, selon lui, remplace Sinadî dans la gestion des cellules d'officiers), est située en 1944 et la troisième en 1950. Le problème est que, selon tous les acteurs (Shâdî n'en est pas un pour la période 1940-1948), Nâsir prête allégeance à Sinâdî, nous le verrons, en 1946, après, bien après le début de la relation avec Labîb. Si une des deux relations précède l'autre, c'est bien celle avec Labîb.

39.'Abd al-Ra'ûf, op. cit., p. 43.

40.Ibid., p. 277-302.

41.Ibid., p. 125-143.

42.Ibid., p. 279.

43.Ibid., p. 127. 
44.a) Le récit des Mémoires est beaucoup plus précis. b) Dans tous les textes, il situe sa « rencontre » avec les Frères peu après sa libération. Or, la date de celle-ci (mars 42) est vérifiable. c) Reste, bien sûr, l'éventualité qu'entre sa première rencontre avec les Frères et son adhésion, il y ait eu un laps de temps très étendu. Mais cela ne semble pas avoir été le cas.

45.Sâdât affirme que lors de sa seconde rencontre avec al-Bannâ (été/automne1940), ce dernier insista beaucoup pour connaître l'identité des officiers collaborant avec lui. Sâdât finit par donner le nom de 'Abd al-Mun'im 'Abd al-Ra'ûf (ce choix, pouvant être interprété de diverses manières, ne nous donne aucune indication sur le degré de collaboration entre les deux hommes. 'Abd al-Ra'ûf peut aussi bien être un membre important qu'un collaborateur périphérique). Lors de rencontres ultérieures, Sâdât aura la surprise de découvrir qu'al-Bannâ connait bien 'Abd al-Ra'ûf et en déduit que l'un est entré en contact avec l'autre. Cf. Sâdât, Révolte, op. cit., p. 100-101. Sâdât ayant été arrêté fin 1942, l'on déduit que le contact al-Bannâ / cAbd al-Ra'ûf a été établi auparavant.

46.'Abd al-Ra'ûf, op. cit., p. 281

47. Mitchell Richard P., op. cit.

48. Hammûda Husayn, op. cit., p. 32.

49.Selon les indications de Hammûda : Il rejoint le 3 ebataillon d'infanterie le 28 juin 1943 (Hammûda, op. cit., p. 25). cAbd al-Ra'ûf l'aborde fin 1943 (ibid.). cAbd al-Ra'ûf le présente à Labîb fin 1943 (ibid., p. 26). Plusieurs rencontres rassemblent ce trio, "jusqu'à ce qu'un profond sentiment de confiance règne ». Puis (à une date non précisée), il est présenté à al-Bannâ. Ensuite l'on recrute cinq autres officiers (Nâsir compris). Il nous semble difficile, vu les précautions à prendre, que la réunion fondatrice, avec la participation des sept officiers, ait eu lieu au « tout début 1944 » (matlac44).

50.Cf. le témoignage de Kamâl al-dîn Husayn in Hamrûsh, Shuhûd thawrat yûlyu, op. cit., p. 338. Dans son interview par Târiq Habîb, il donne beaucoup plus de détails, mais moins de dates précises. Notons qu'il a indiqué s'être souvent rendu aux « leçons du mardi » d'al-Bannâ, et cela avant même d'entrer en contact avec 'Abd al-Ra'ûf et Nâsir et d'adhérer « formellement » aux Frères.

51.Cf. sa confession in Shukrî Ghâlî, op. cit., p. 111, puis p. 114. Cf. un article du même Muhyî al-Dîn, écrit dans les années 1950, cité par Abû al-Magd, op. cit., p. 141. Cf. ses Mémoires, op. cit., p. 43 et suivantes. Khâlid Muhyî al-Dîn ne fait la connaissance de Nâsir qu'en décembre 1944 et ils ne se revoient une seconde fois (par hasard) que 45 jours après, voire davantage (dans l'article cité par Abû al-Magd, écrit dans les années 1950, il parle de plusieurs mois). Il se peut que Muhyî al-Dîn ait adhéré aux Frères avant de faire la connaissance de Nâsir, mais il dit le contraire dans sa " confession » et dans ses Mémoires (par contre, l'article cité par Abû al-Magd est ambigu, en ce qu'il affirme avoir milité avec 'Abd al-Ra'ûf - non nommé, mais désigné - dans un même groupe, depuis 1942 : ceci désigne-t-il les Frères ou la constellation aviateurs / Sâdât / cAzîz al-Masrî ? Le second cas de figure est de loin le plus probable. C'est d'ailleurs l'explication que donne Muhyî al-Dîn dans les deux autres textes, sans voir que cette constellation était composée de divers groupes et qu'il traita surtout avec celui dont cAbd al-Ra'ûf ne faisait probablement pas partie). Quoi qu'il en soit, la constitution de la cellule " fondatrice » ne peut qu'être postérieure à sa présentation à Nâsir.

52. Ukâsha, op. cit., p. 36. Pour Shâf î, voir son interview in al-Imâm Salâh, 1993, Husayn al-Shâf-î wa-asrâr thawrat yûlyû wa-hukm al-Sâdât, Le Caire, Maktab Osiris, p. 44-45. Par 
contre, interrogé par cAbdallâh Imâm (dans un ouvrage publié en 1995), il a fortement nuancé ses propos : « peut-être certains d'entre nous avaient effectué un passage par les Frères [avant de rejoindre le mouvement des Officiers libres], mais les conditions d'adhésion aux Officiers libres stipulaient la non-adhésion à une autre organisation ». Cf. Imâm, cAbd Allâh, Wagîh Abâza : safahât min al-nidâl al-watanî, tome 1, Le Caire, 'Arabiyya li-l-tibâca wa-l-nashr, op. cit., p. 176.

53.Témoignage de Amîn Huwaydî in Hamrûsh : Shuhûd thawrat yûlyû, op. cit., p. 85. 54.'Abd al-Ra'ûf, op cit., p. 129. Après avoir rappelé que les sept membres de la cellule fondatrice prêtèrent serment d'allégeance, il ajoute : « Quant aux autres officiers, certains prêtèrent serment, et d'autres non. "

55.Muhyî al-Dîn, op. cit., p. 43 et suivantes ; Shukrî, op. cit., p. 111 et suivantes.

56.Hammûda Husayn, op. cit., p. 33. Il indique que chacun des sept membres de la cellule fondatrice constitua une cellule composée au maximum de sept membres. Il ajoute qu'aucun des sept membres de la cellule fondatrice ne donna aux six autres l'identité des membres de sa propre cellule, pour des raisons de sécurité. L'estimation de Tuayma est citée par Beattie, op. cit., p. 49, note 69. Beattie affirme que 100 constitue un minimum. Nous pensons (outre le texte de Hammûda, voir infra nos déductions certes fragiles - à partir du « budget » du groupe) qu'il s'agit d'un maximum, très probablement au-dessus de la réalité. Mais il est incontestable que ce groupe d'activistes est le plus influent de l'époque au sein de l'armée.

57.Hammûda Husayn, op. cit., p. 34.

58. Ukâsha Tharwat, 1987, Mudhakkirâtî fîl-siyâsa wa-l-thaqâfa, tome 1, Le Caire, Madbûlî, p. 35-36.

59.Al-Imâm, op. cit., p. 43.

60.Interview publiée par l'hebdomadaire Uktûbar, le 19-07-87.

61.Par exemple Shâdî Salâh, op. cit., p. 179.

62.Et, bien sûr, cAbd al-Hakîm ‘Âmir. Mais ce dernier n'a pas laissé de témoignage.

63.Shâdî, op. cit., p. 168. Auparavant, p. 166, il indique que les « recruteurs » ne devaient pas « immédiatement » dévoiler l'identité Frère musulman de l'organisation. Page 168, il explique que Nâsir ne le faisait pratiquement jamais, estimant toujours que le temps propice n'était pas venu.

64.Ibid.

65.Ibid.

66.Témoignage de Tahâwî in Hamrûsh, Shuhûd thawrat yûlyû, op. cit., p. 14-15.

67.Shâdî, op. cit., p. 167.

68.Il est difficile aujourd'hui de savoir à quel point dogmatisme et pragmatisme se retrouvaient au sein de la base Frère, si on peut parler d'un sommet « dogmatique » et d'une base " pragmatique » ou vice versa, et dans quelles proportions.

69.Hammûda Husayn, op. cit., p. 149.

70.Même si nous n'avons aucun support documentaire, nous pouvons penser que Nâsir a dû faire une remarque sur le thème : une telle stratégie n'exploite pas la présence de militaires au sein du mouvement et leur savoir-faire en matière de " coercition » et/ou de résistance à l'occupant, et la formuler en insistant sur le rôle des officiers dans le mouvement. Dans cette optique, il est possible et intéressant (mais bien sûr peu probant), de relier une éventuelle réflexion de Nâsir sur les « commandants » et les " commandés » avec le récit de Bughdâdî, qui rapporte ses premiers entretiens avec le Guide suprême en 1940-1941 : «Al-Bannâ justifia sa proposition [de fusion entre les Frères musulmans et le groupe des aviateurs et de Sâdât] en affirmant qu'il avait les 
soldats, c'est-à-dire les adhérents à son mouvement, qui étaient, selon son estimation, un quart de million à l'époque, et qu'il avait besoin de commandants capables de les diriger, et que les officiers seraient ces commandants. »Cf. al-Bughdâdî, op. cit., p. 13-14. L'éventuelle remarque sur le rôle de « commandants » des officiers, reprend donc, si nous ne nous trompons pas, un terme utilisé par al-Bannâ. Selon nous, elle dut s'inscrire dans le cadre de la contestation d'une stratégie (celle des Frères) reléguant le problème de l'occupation britannique au second plan. Cette interprétation, dont la base documentaire est bien sûr fragile - c'est un euphémisme -, nous semble plus pertinente que la version de Hammûda. Nous pensons qu'un « obsédé » de la prise du pouvoir ne se serait pas exprimé avec autant de franchise et de brutalité.

71.Shukrî, op. cit., p. 112

72.Interview de cAbd al-Khâliq in Kâmil Rashâd, 1990, cAbd al-Nâsir alladhî lâ tarifuhu, Le Caire, al-Giddâwî li-l-nashr, 174 pages, p. 91.

73.Hammûda Husayn, op. cit., p. 32-33.

74.Muhyî al-Dîn mentionne des réunions auxquelles participent des officiers qui, selon toute probabilité, ne font pas partie de la même cellule. Muhyî al-Dîn, op. cit., p. 43-44.

Dans le cas des mémoires de 'Abd al-Ra'ûf, l'impression de flou organisationnel est plus " diffuse »; elle n'en demeure pas moins réelle.

75.Cf. supra, et cukâsha, op. cit., p. 35-36.

76.Shâdî, op. cit., p. 166.

77.Voici le type même de formulations qui illustrent la thèse d'Abû Bâshâ : l'idéologie du takfir n'est pas propre à Qutb. Elle représente un risque inhérent, congruent au discours du mouvement et à sa prétention à monopoliser la représentation de l'islam. Si al-Bannâ était très prudent, ses disciples l'étaient moins.

78.Shâdî, op. cit., p. 174.

79.Interview de Nâsir par Morgan pour le Sunday Times, citée par Imâm cAbd Allâh, alNâsiriyya, op. cit., p. 33-34. Sâdât, Al-bahth can al-dhât, op. cit., p. 31 et suivantes

80.Cf. les témoignages cités de cUkâsha et de Muhyî al-Dîn et celui de Salâh Nasr, op. cit., p. 68. (Nasr ne sera jamais Frère).

81.Gershoni et Jankowski, op. cit., p. 4-5. lls ajoutent : « Hizbiyya had been rarely used in the 1920s, by the 1930s it was becoming a widely accepted term in the Egyptian political lexicon, a symbol of the bankrupcy of Egyptian public life.»

82.Le point fort de l'ouvrage de Muhsin Muhammad (Man qatala, op. cit.) réside précisément dans son exposé systématique et intelligent du jeu politique des Frères. 83.Publié par la revue Tahrîr, les 8 et 15 octobre 1953 et cité par Hammûda cÂdil, 1989, ‘Abd al-Nâsir : al-hurûb al-khaffiyya maca al-mukhâbarât al-amrikiyya, Le Caire, al-Dâr alcarabiyya, 444 pages, p. 64.

84.Shâdî, op. cit., p. 169. Shâdî se fonde d'ailleurs sur une déclaration de Kamâl al-Dîn Husayn à Sâmi Gawhar, publiée dans 1975 Al-sâmitûn yatakallamûn, 1975, Le Caire, almaktab al-masrî al-hadîth, p. 33. Husayn affirme que Nâsir aimait à dire qu'une partie de ses recrues avait été « tirée des bars et des fumeries de haschich » (plusieurs Officiers libres, et non des moindres, étaient des fumeurs célèbres. Certains figuraient parmi les plus intelligents et/ou les plus courageux du mouvement). Il est fort possible que Nâsir ait dit cela, sans se douter de l'interprétation qu'on en ferait après sa mort. Hasan al--Ichmâwî cite également des railleries de Nâsir en ce sens. Cf. al-'Ishmâwî, cité par Imâm, in cAbd al-Nâsir wa-l-ikhwân..., op. cit., p. 39 et suivantes.

85.Ou, dans le meilleur des cas, pilule très amère. 
86.Pour ne donner qu'un exemple des vues des officiers nationalistes sur le problème de l'autonomie de la science, citons Khâlid Muhyî al-Dîn : « Chez moi, à domicile, avec ma femme, mes enfants et ma famille, et hors de chez moi, avec les gens, mon comportement est celui d'un Égyptien arabe et musulman. Pour cultiver la terre, pour engendrer de l'électricité, pour faire marcher une usine, j'aurai recours à la science, qui n'a pas de nationalité. »Cf. sa confession in Shukrî, op. cit., p. 128. Noter que Khâlid Muhyî al-Dîn a évité de dire " ni nationalité ni religion ", alors que cela est clairement sous-tendu par la logique de sa phrase et du contexte. Cet exemple, et surtout cette omission, sont caractéristiques de l'attitude de ces officiers. L'on évite la confrontation entre les deux domaines, parce que si confrontation il y a, il sera nécessaire de proclamer la primauté du religieux. Mais, en pratique, la science est autonome et dotée de sa propre logique.

87.Cette soumission au contrôle du religieux semble explicitement énoncée par le discours d'al-Bannâ, comme le montre le travail d'Ibrâhîm al-Bayyûmî Ghânim. Il cite un article d'al-Bannâ dans le Manâr. Le Guide suprême y explique que le Coran doit déterminer ce qui, des acquis de la civilisation (et de la science) occidentale, peut être adopté, et ce qui doit être rejeté. Cf. Ghânim Ibrâhîm al-Bayyûmî, op. cit., p. 238 et suivantes. Si ce principe est (plus ou moins, selon les cas) défendable, voire valide en général, il constitue, en ce qui concerne la science, un risque, puisqu'il ne nous dit pas, entre autres, qui interprétera le Coran et comment. Outre l'exemple mentionné infra, la question se pose avec acuité, par exemple, pour la biologie, la psychiatrie et la psychanalyse.

88.Sur le rapprochement tactique entre les Frères musulmans et Ismâî̂l Sidqî pasha (et Fârûq), voir Ramadân, op. cit., p. 66 et suivantes (l'achat du papier à des prix subventionnés est mentionné p. 67).Cf. également Mitchell Richard, op. cit., p. 42 et suivantes. Cf. Imâm, cAbd al-Nâsîr wa-l-ikhwân..., op. cit., p. 8-9. Muhammad Muhsin, Sana min umr Misr, op. cit. (ce livre, comme ceux de Muhammad, doit beaucoup aux archives du FO britannique), et, du même auteur, Man qatala..., op. cit., p. 100 et suivantes. Pour une défense des vues des Frères, voir Shâdî, op. cit., p. 82 et suivantes, et Kamâl, op. cit., p. 138.

89.Pour formuler notre pensée autrement, l'on pourrait dire que la cause nationale est quelquefois instrumentalisée, ou sacrifiée, par lui, à d'autres fins. Pour les officiers, ceci n'est pas acceptable.

90.Al-Imâm, op. cit., p. 43.

91.Elle devrait au moins être formulée différemment : si les Frères souhaitent exploiter politiquement les avantages que procure leur statut revendiqué de défenseurs et de porte-parole de la religion et des valeurs absolues, ils devraient au moins en accepter les contraintes. Mais l'accusation de perversité est injuste.

92.Par « acteurs », nous désignons autant les officiers que la plupart des militants Frères de l'époque.

93.C'est l'approche des Frères et des autres associations islamiques. Les mémoires de Shâdî et de Ahmad cÂdil Kamâl en sont une illustration. Cf. aussi, Ghânim, Al-fikr alsiyâsî..., op. cit., p. 67 et suivantes, sur le contexte culturel et intellectuel de l'Égypte post-Première Guerre mondiale, et notamment $\mathrm{p}$. 91. Sa formulation, partisane, et différente de la nôtre, illustre néanmoins nos propos. Notons par ailleurs que, selon lui, les diverses associations islamiques avaient le tort de ne n'avoir qu'une vision « partielle » de l'islam, et/ou de ne se concentrer que sur le comportement individuel, 
sans une pensée de la totalité, de l'action collective (le jihâd) et de la réforme sociétale globale. Il y avait un vide que les Frères combleront.

94.Shâdî, op. cit., p. 41.

95.Hammûda Husayn, op. cit., p. 29, Sâdât, Al-bahth can al-dhât, op. cit., p. 31-32.

96.Le soufisme, dans ses formes « dégénérées », est jugé par les islamistes (pas seulement par les Frères) comme une, voire la cause de la décadence. $C f$. Ghânim, op. cit., et Kamâl, op. cit., p. 37. Une importante exception semble avoir été al-Bannâ luimême, qui identifiait les causes de la décadence comme étant la «tyrannie des femmes », le « luxe corrupteur des dirigeants », les « controverses doctrinales », le renoncement à la « commanderie du bien ». Cf. Ghânim, ibid., p. 211 et suivantes. Ghânim conteste la pertinence historique (i.e. ce n'est pas ainsi que les choses se sont passées) de ce jugement mais aussi, semble-t-il, sa justesse sociologique, (i.e. ce n'est pas une règle observable), car il affirme que ce sont les « symptômes » du mal plutôt que ses causes. Il explique le diagnostic d'al-Bannâ par une prise de position sur les enjeux et débats des années trente - mérites de l'occidentalisation des modes de vie et de la société. Ghânim critique également l'omission, par al-Bannâ, de l'absence de shûrâ comme facteur de corruption du politique et de décadence sociétale, omission qu'il tente également d'expliquer par le contexte des années trente - et c'est moins convaincant. Pour une approche intéressante, bien que brève, des différentes perceptions du soufisme et une définition du «bon » et du «mauvais » soufisme, par un proche d'al-Bannâ, cf. cAbd al-Halîm Mahmûd, 1981, Al-Ikhwân al-Muslimûn, ahdâth sinâcat al-târîkh, tome 2, Le Caire, Dâr al-Da'wa, 566 pages, p. 335-336.

97. Abd al-Halîm a consacré une importante partie du second tome de ses Mémoires à l'étude de l'apport de Hasan al-Bannâ. Cf. cAbd al-Halîm, ibid., p. 336.

98.Shâdî explique en substance que la position d'al-Bannâ permet d'islamiser la modernité, ou de montrer que les acquis de celle-ci (sur l'esclavage, sur le droit des minorités, sur la guerre, pour reprendre ses propres exemples) ne sont pas contraires aux préceptes et à l'essence de l'islam. Cf. Shâdî, op. cit., p. 42 : «C'étaient des questions que j'avais (jusqu'à ce moment, la rencontre avec al-Bannâ) évitées, de peur de la perdition dans le labyrinthe du kufr, car j'avais cru que la position de l'islam était une position que refuserait la raison et que n'approuveraient pas les us de notre époque. » Ahmad cÂdil Kamâl ne parle pas d'originalité doctrinale, mais de révélation (ou de rappel) de l'essence de l'Islam (haqîqat al-islâm wa lubbihi), épurée des cortèges et processions du soufisme et de l'escroquerie (dajal) des « innovateurs ", essence totalement en accord avec la raison. Cf. Kamâl, op. cit., p. 37. Tout ceci revient à dire, indirectement, qu'al-Bannâ a l'énorme mérite de mettre un terme à la «forclusion » de l'islam par le politique.

99.Y compris l'écrasante majorité des officiers marxistes.

100.Olivier Carré a qualifié la doctrine de Rashîd Ridâ, un des principaux « maitres » d'al-Bannâ, de « néo-hanbalite », « peu conforme à la grande tradition de la pensée islamique ».Cf. Carré, L'utopie..., op. cit., p. 9 et suivantes. Si nous avons bien compris ses écrits, le terme peut s'appliquer à al-Bannâ. Nous ne pensons pas que le constat eût gêné ce dernier. Il aurait probablement répondu en affirmant qu'il avait puisé, dans le corpus islamique classique, ce qui était le plus approprié pour incarner l'essence (lubb, jawhar), les fondements, (usûl) de l'islam, face à la spécificité, à la nouveauté des défis colonialistes et de l'acculturation. Et/ou, que l'enjeu, pour lui, était, d'une part, le retour à l'esprit de l'islam des origines, et, de l'autre, le rassemblement des musulmans 
d'aujourd'hui, par delà leurs divisions doctrinales et religieuses. Sur les enjeux doctrinaux vus par al-Bannâ, cf. cAbd al-Halîm, op. cit., p. 338 et suivantes.

101.Mitchell, op. cit., p. 210, puis p. 214 et suivantes, sur le rejet du " factionnalisme » doctrinal et des excès du soufisme. cAbd al-Halîm, op. cit., p. 336 et suivantes, pour la " synthèse » opérée par al-Bannâ.

102.Kamâl, op. cit., p. 38.

103.Mitchell, op. cit., p. 214 ; cAbd al-Halîm, op. cit., p. 336 ; Ghânim, op. cit., p. 144.

104.Kamâl, op. cit., p. 107.

105.Shâdî, op. cit., p. 130

106.Dûh Hasan, 1993, Al-irhâb al-marfûd wa-l-irhâb al-mafrûd, Le Caire, Dâr al-Ittisâm, 153 pages, p. 13.

107.Voir également le témoignage de UUmar al-Tilmisânî (troisième Guide suprême), rapporté in Muhammad, Muhsin, Man qatala... op. cit., p. 369-370.

108.Cité par cAbd al-Halîm, op. cit., p. 345.

109.Mitchell, op. cit., p. 210. Notons que le goût pour les controverses est identifié par al-Bannâ comme une des causes de la décadence. Pour être équitable, ajoutons qu'il avait conscience du fait qu'un consensus sur tout était « impossible ». Cf. Ghânim, op. cit., p. 216.

110.« Allâh est Grand, à Allâh les louanges. Allâh est notre Fin, Le Prophète notre zaĉm, le Coran notre Constitution, le jihâd notre Voie, la mort sur la voie d'Allâh (pour Allâh) notre plus noble espoir.»

111.En l'occurrence, Hasan al-Bannâ a, si l'on ose dire, réhabilité le concept de jihâd en tant que guerre ou combat béni de Dieu contre les kuffâr (infidèles).

112.Hammûda, op. cit., p. 26 et suivantes. Sâdât, Al-bahth can al-dhât, op. cit., p. 31 et suivantes.

113.Par exemple Muhyî al-Dîn, op. cit., p. 43.

114.Pour celle de Khâlid Muhyî al-Dîn, voir Muhyî al-Dîn, op. cit., p. 39, p. 44 ; ou sa confession in Shukrî, op. cit., p. 111, p. 115. Pour celle de cUkâsha, cf. cUkâsha, op. cit., p. 37 et suivantes. Pour celle d'al-Bughdâdî, $c f$. son témoignage in Hamrûsh, Shuhûd thawrat yûlyû, op. cit., p. 212, p. 218, et Sâ̂d, cAbd al-Mughnî, op. cit.

115.Confession de Muhyî al-Dîn in Shukrî, op. cit., p. 111, p. 115.

116. Ukâsha, op. cit., p. 37.

117.Kamâl, op. cit., p. 299-300.

118.Plusieurs dates sont proposées. Sur les différentes versions, voir Muhammad, Man qatala..., op. cit., p. 370. Un des acteurs interviewés par Muhsin Muhammad, l'avocat Frère Fahmî Abû Ghadir, va jusqu'à affirmer que l'organisme secret fut créé en 1935. Cf. Muhammad, op. cit., p. 370. Ramadân, op. cit., p. 44, cite la déposition (en 1954) de Khamîs Himayda, lequel affirme que l'organisme secret fut créé en 1942 ou « un peu avant ». Nous retenons celle (1940) avancée par al-Halîm, in ‘Abd al-Halîm, op. cit., tome 1, p. 258, car ce dernier est un des fondateurs de l'organisme secret et un témoin précis. Shâdî a aussi retenu cette date. Shâdî, op. cit., p. 127. Kamâl, op. cit., p. 120, et al--Uqâlî, in Kâmil, Asrâr al-ilâqqa al-khâssa..., op. cit., p. 8, donnent pour date 1938, également envisagée par Carré, in Carré et Michaud, op. cit., p. 29.

119.Une déclaration de Hasan al-Bannâ, rapportée par Khâlid Muhammad Khâlid, in Khâlid, op. cit., p. 280. Shâdî, op. cit., p. 140-1, affirme que l'organisme secret luttait contre « le défi des sionistes et la répression des gouvernements d'agents (de traîtres) ». Khâlid, op. cit., p. 127, explique la création de cet organisme par les nécessités de la lutte anti-britannique et anti-sioniste. Explication également avancée 
par Kâmil al-Sharîf, cité par 'Ala' al-Hadîdî in : " al-Kifâh al-musallah wa-dawr jadîd fî al-kifâh al-watanî, in 'Abbas Ra'ûf (éd.), 1995, Al-ilâqât al-misriyya al-britânniyya, 1951-1954, Le Caire, Éditions du Centre de recherches politiques et stratégiques d'alAhrâm, 220 pages, p. 23. Ou par 'Umar al-Tilmisânî, cité in Muhammad, Man qatala..., op. cit., p. 369. Kamâl, op. cit., p. 120, fournit le même type d'explication et ajoute que l'expansion de l'organisme secret date de 1945. Si nous pouvons à la rigueur accorder le bénéfice du doute à al-Bannâ en ce qui concerne ses intentions premières (mais, sur ce point, nous ne sommes pas enclin à le faire, et nous ne sommes pas le seul), il reste que l'organisme secret fut vite utilisé à d'autres fins. Al-cUqâlî, in al-Hakîm, op. cit., p. 8 et suiv., explique que l'organisme secret était « l'atelier » du mouvement, son bras armé préparant la prise du pouvoir. Lors de son témoignage, cAbd al-Magîd Hasan, l'assassin du Premier ministre Nuqrâshî, affirma qu'on lui avait expliqué, lors de son recrutement, que le mouvement, pour ressembler totalement à la prédication du Prophète Muhammad, se devait d'avoir recours aux armes. Cité in Ramadân, op. cit., p. 50-51. Ramadân affirme que les dirigeants de l'organisme affirmaient aux recrues que l'OS avait pour but la lutte anti-britannique et qu'on ne les endoctrinnait qu'après, et progressivement.

120.Voir Kamâl, op. cit., p. 300. Sur le rôle de Sayyid Sâbiq auprès de l'organisme secret, voir par exemple Ramadân, op. cit., p. 58 ; ou Khâlid, op. cit., p. 284, p. 286 (et p. 282, pour confirmation de la version de Ramadân).

121.Sâbiq Al-Sayyid, 1990, Fiqh al-sunna, trois tomes, Le Caire, al-fath li-l-iclâm al-carabî, 122.Sâbiq, ibid., tome 3, p. 111-196.

123.'Abd al-Ra'ûf, op. cit., p. 129. Shâdî, op. cit., p. 190, affirme que Mahmûd Labîb faisait « très confiance » à Nâsir. Ahmad Abû al-Fath, qui ne donne pas de précisions sur ses " sources », affirme également que " Nâsir gravit les échelons (de l'organisme secret) et à la fin de 1946, il se trouvait en rapport direct avec cAbd al-Rahmân al-Sinadî. 'Abd alNâsir avait pour tâche d'assurer l'entrainement des membres de l'OS à l'emploi des armes et aux actes de sabotage. »Cf. Abî al-Fath (Abû al-Fath) Ahmad, 1962, L'affaire Nâsir, Paris, Plon, 337 pages, p. 177. Nous retenons le principe du témoignage, mais signalons que Nâsir (et les six autres membres de la cellule fondatrice) fut, semble-t-il, immédiatement (dès son adhésion à l'oS) en contact avec al-Sinadî.

124.Hammûda, op. cit., p. 33, p. 74.

125.Pour une étude brève de l'évolution des relations entre le Palais et les Frères musulmans, voir Sâlîm, op. cit., p. 706 et suivantes.

126.Muhyî al-Dîn, op. cit., p. 47.

127.Muhyî al-Dîn, op. cit., p. 107. Muhyî al-Dîn parle de la « haine » de cÂmir pour les Frères.

128.Cf. par exemple Kamâl, op. cit., p. 138 et suivantes. Exemple simple de ce que nous appelons une lecture en filigrane : p. 139, Kamâl affirme que Sidqî était l'ennemi du Wafd. Sous-entendu : et pas de la nation dans sa totalité.

129.Shâdî, op. cit., p. 83.

130.En s'opposant au projet de traité Sidqî-Bevin.

131.Nous serions tentés d'écrire - mais nous avons le bénéfice du recul, et les passions de l'époque se font bien lointaines - qu'al-Bannâ a eu « tout faux » dans l'épisode :

l'opinion avait le droit de se méfier de Sidqî quand celui-ci fût nommé par le roi, et alBannâ eut tort de se démarquer. Par contre, l'accord Sidqî-Bevin méritait un meilleur sort et al-Bannâ aurait dû le défendre, ne serait-ce que pour prouver qu'il avait eu raison de « parier » sur Sidqî. Mais ce dernier point, certes exact, est probablement... 
très injuste : il était très difficile, dans le contexte de polarisation de l'époque, de signer ou de défendre un accord avec les Britanniques, quelles qu'en soient les vertus. Les pratiques discursives de l'époque rendaient, nous l'avons dit, intenable toute position non maximaliste.

132.Ce n'était pas vrai. Un « réaliste » (pas forcément au bon sens du terme) serait plus approprié.

133.Outre les témoignages des Officiers libres, nous disposons de ceux de civils "nationalistes ", ayant eux aussi éprouvé de la sympathie pour les Frères musulmans et qui « révisent » leur jugement après cet appui à Sidqî. Cf. par exemple Abû al-Magd, op. cit., p. 28 et suivantes, et p. 36 et suivantes.

134.Rapportées - et déplorées - par Shâdî, op. cit., p. 75. Shâdî, une fois encore, ne dit pas « les Frères musulmans », mais « l'islam ». Il est toutefois très probable, voire clairement évident, que Tawfîq, non pratiquant (en 1946-1948) mais croyant, pensait aux Frères musulmans, et non à sa religion. Et si, par hasard, il a effectivement pensé que foi et nationalisme s'excluaient, ceci « exclut » également les Frères.

135.Interview de Muhsin 'Abd al-Khâliq in Fawzî Mahmûd, 1990, Al-dhubbât al-ahrâr yatahaddathûn, Le Caire, Madbûlî, p. 161.

136.Témoignage de Fath Allah Rifaat in Hamrûsh, Shuhûd..., op. cit., p. 256.

137.Pour les vues des Frères, et leur appréciation du jihâd des mineurs, voir le beau texte d'al-Sharîf Kâmil, 1987, Al-ikhwân al-muslimûn fì harb filistîn, Mansûrah, Dâr AlWafâ', p. 41, p. 49 (le texte date de 1951). Il rappelle que le Prophète enterra lui-même un très jeune martyr.

138.Shayegan Daryush, 1982, Qu'est-ce qu'une révolution religieuse? Paris, Les Presses d'aujourd'hui. Roy Olivier, 1992, L'échec de l'islam politique, Paris, Collection Esprit/Seuil. 139.En l'absence (à notre connaissance) d'études, à partir de cette perspective, sur les groupes islamistes, nous ne pouvons que - mais le faisons volontiers - renvoyer à l'analyse de l'œuvre de Cochin (sur les jacobins) par Furet François, 1988, Penser la Révolution française, Paris, Folio histoire, p. 266 et suivantes.

140.Témoignage de Muhsin cAbd al-Khâliq in Hamrûsh, Shuhûd thawrat yûlyu, op. cit., p. 368. Et aussi son interview in Fawzî, op. cit., p. 161.

141.Noter deux facteurs qui contribueront à aggraver la situation : d'une part, les forces de l'ordre ne sont pas assez nombreuses pour assurer le maintien de l'ordre et les tâches répressives (elles sont débordées et ses membres sont fatigués). De l'autre, une quantité indéterminée et incontrôlable d'armes circule dans le pays, objet de divers trafics : nous sommes au lendemain de la Seconde Guerre et nombreux sont les soldats étrangers qui ont vendu leurs armes à des Égyptiens. Lesdites armes sont souvent plus modernes que celles dont disposent les forces de l'ordre! Tout ceci représente une évolution très dangereuse. $C f$. Muhammad, op. cit., p. 93, qui cite des dépêches diplomatiques britanniques.

142.Le Palais, qui a recours à l'assassinat pour éliminer ses adversaires (cf. infra), est l'autre principal responsable. Le parti d'Ahmad Husayn est, à un degré moindre, un troisième " coupable ». Pour des exemples des actions des Frères, voir : Sâlim, op. cit., p. 706 et suivantes. 'Allâm, op. cit., p. 43 et suivantes, Abû Bâchâ, op. cit., p. 69-70 ; Kamâl, op. cit., p. 142, p. 144, puis p. 173-175, p. 178-179, p. 188-189, etc. Ramadân, op. cit., p. 68 et suivantes. On trouvera un inventaire impressionnant in Muhammad, Man qatala, op. cit., p. 372 et suivantes, p. 384 et suivantes.

143.Outre les responsabilités des chefs « institutionnels » des Frères, tels al-Bannâ et al-Sinadî, des adhérents constituaient leur propre « organisme secret », commettant les 
actes de violence leur semblant nécessaires. Dans ses Mémoires, Ahmad cÂdil Kamâl explique qu'une des responsabilités de l'organisme secret était de «liquider » (par la cooptation, probablement) ces « organismes secrets » informels, pour que le mouvement ne perde pas le contrôle des actes des « enthousiastes ». Cf. Kamâl, op. cit., p. 149.

144.Article publié par le journal d'opposition $a$

INDEX

Mots-clés : Frères musulmans, histoire, Officiers libres

\section{AUTEUR}

TEWFIK ACLIMANDOS

Cedej 